\title{
Molecular Diversity of Glutamatergic and GABAergic Synapses from Multiplexed Fluorescence Imaging
}

\author{
Eric Danielson, ${ }^{1}$ Karen Perez de Arce, ${ }^{2}$ Beth Cimini, ${ }^{3}$ Eike-Christian Wamhoff, ${ }^{1}$ Shantanu Singh, ${ }^{3}$ \\ Jeffrey R. Cottrell, ${ }^{2}{ }^{-}$Anne E. Carpenter, ${ }^{3}$ and ${ }^{\circ}$ Mark Bathe ${ }^{1}$
}

https://doi.org/10.1523/ENEURO.0286-20.2020

${ }^{1}$ Department of Biological Engineering, MIT, Cambridge 02142, MA, ${ }^{2}$ Stanley Center for Psychiatric Research, Broad Institute of MIT and Harvard, Cambridge 02142, MA, and ${ }^{3}$ Imaging Platform, Broad Institute of MIT and Harvard, Cambridge 02142, MA

\begin{abstract}
Neuronal synapses contain hundreds of different protein species important for regulating signal transmission. Characterizing differential expression profiles of proteins within synapses in distinct regions of the brain has revealed a high degree of synaptic diversity defined by unique molecular organization. Multiplexed imaging of in vitro rat primary hippocampal culture models at single synapse resolution offers new opportunities for exploring synaptic reorganization in response to chemical and genetic perturbations. Here, we combine 12-color multiplexed fluorescence imaging with quantitative image analysis and machine learning to identify novel synaptic subtypes within excitatory and inhibitory synapses based on the expression profiles of major synaptic components. We characterize differences in the correlated expression of proteins within these subtypes and we examine how the distribution of these synapses is modified following induction of synaptic plasticity. Under chronic suppression of neuronal activity, phenotypic characterization revealed coordinated increases in both excitatory and inhibitory protein levels without changes in the distribution of synaptic subtypes, suggesting concerted events targeting glutamatergic and GABAergic synapses. Our results offer molecular insight into the mechanisms of synaptic plasticity.
\end{abstract}

Key words: machine learning; multiplexed imaging; synaptic plasticity; synaptic scaling

\section{Significance Statement}

An immense number of proteins are present at synapses to regulate synaptic function. Recent efforts characterizing synaptic protein expression patterns suggest their differential expression gives rise to diverse synapse subpopulations. In this work, we use multiplexed fluorescence imaging with advanced image analysis to detect and quantify protein levels using CellProfiler. We apply our technique to develop a robust approach for unbiased synaptic subtype identification based on protein expression profiles using uniform manifold approximation and projection (UMAP) dimensional reduction and hierarchical density-based spatial clustering of applications with noise (HDBSCAN) clustering. Finally, we apply this approach to examine synaptic diversity in cultured hippocampal neurons and examine the molecular events of 11 proteins at excitatory and inhibitory synapses following synaptic scaling.

\section{Introduction}

Synapses contain complex proteomes that organize into multiprotein signaling complexes (Husi et al., 2000; Collins et al., 2006). There appears to be a high degree of

Received June 29, 2020; accepted December 7, 2020; First published December 16, 2020.

The authors declare no competing financial interests. diversity in the expression, stoichiometry, and organization of these proteins across scales from individual

Author contributions: M.B., E.D., K.P.d.A., J.R.C., and A.E.C. designed research; E.D. and K.P.d.A. performed research; B.C. and E.-C.W. contributed unpublished reagents/analytic tools; E.D., K.P.d.A., B.C., and S.S. analyzed data; M.B., E.D., K.P.d.A., B.C., E.-C.W., S.S., J.R.C., and A.E.C. wrote the paper. 
synapses to the entire brain (Emes and Grant, 2012; Roy et al., 2018; Zhu et al., 2018). While it is unknown how many classes of synapses exist, there are over 1000 genes that encode synaptic proteins (Husi et al., 2000; Peng et al., 2004; Collins et al., 2005, 2006; Emes et al., 2008; Bayés et al., 2011, 2012, 2017; Emes and Grant, 2011; Distler et al., 2014). The differential expression of these proteins across distinct brain regions, as well as differential spatial-temporal expression during development, suggest significant synaptic diversity. Immunofluorescence labeling of two differentially expressed excitatory scaffolding proteins was used to examine synaptic diversity throughout the mouse brain (Zhu et al., 2018) however, to date how synaptic diversity is affected by synaptic scaling has not been investigated. Synaptic scaling maintains neuronal homeostasis via global changes in expression of multiple synaptic proteins targeting both excitatory and inhibitory synapses to prevent runaway neuronal excitability (Turrigiano et al., 1998; Turrigiano and Nelson, 2000, 2004; Turrigiano, 2008,2012 ). Examination of the entire molecular composition of individual synapses using techniques that can survey the entire proteome, such as mass spectrometry, would be ideal for characterizing synapses. However, synapses are $\sim 2 \mu \mathrm{m}$ in size; and while advances in mass spectrometry-based imaging have achieved 1$\mu \mathrm{m}$ resolution (Zavalin et al., 2015), the majority of commercial matrix-assisted laser desorption/ionization (MALDI) mass spectrometers are not sufficiently accurate for examination of individual synapses. Hence, microscopy techniques, such as immunofluorescence, remains the optimal technique for the examination of individual synapses. However, conventional fluorescence microscopy is generally limited to four channels as a result of the maximal spectral resolution of organic and biomolecular fluorophores. This limitation presents a challenge to comprehensive analysis of synaptic architecture because of the large number of different protein species within each synapse.

Multiplexed imaging techniques are particularly useful for studying neuronal synapses, and investigating the coordinated assembly of dozens to hundreds of distinct proteins involved in synaptic development, function, and plasticity. Probe-based imaging for sequential multiplexing (PRISM) is a recently introduced multiplexed imaging technique that uses single-stranded DNA (ssDNA)-conjugated antibodies or peptides with complementary fluorescently labeled single-stranded locked nucleic acid (ssLNA) imaging probes to sequentially visualize multiple

This work was supported by the National Institutes of Health Grant R01MH112694 (to M.B. and J.R.C.) and the National Science Foundation Physics of Living Systems Grant 1707999 (to M.B.). J.R.C. was also supported by funding from the Stanley Center for Psychiatric Research.

Correspondence should be addressed to Anne E. Carpenter at anne@ broadinstitute.org or Mark Bathe at mark.bathe@mit.edu.

https://doi.org/10.1523/ENEURO.0286-20.2020

Copyright $\odot 2021$ Danielson et al.

This is an open-access article distributed under the terms of the Creative Commons Attribution 4.0 International license, which permits unrestricted use, distribution and reproduction in any medium provided that the original work is properly attributed. synaptic targets in situ (Guo et al., 2019). With this approach, the affinity of the ssLNA imaging probes is salt dependent, allowing multiple synaptic targets to be imaged within the same sample through sequential rounds of imaging first in physiological salt buffer, followed by rapid imaging-strand removal in low-salt buffer. This method of imaging prevents the neuronal sample disruption that occurs with alternative multiplex imaging techniques (Gerdes et al., 2013; Lin et al., 2015). PRISM has been used to quantify changes in synaptic protein levels, co-expression profiles, and synapse-subtype compositions following blockade of action potentials with tetrodotoxin (TTX) treatment (Guo et al., 2019). This analysis revealed that $\Pi T X$ induces a coordinated reorganization of excitatory presynaptic and postsynaptic proteins. However, structural plasticity in response to chronic activity changes occurs in both excitatory and inhibitory synapses which was not addressed in that study.

Here, we used PRISM to measure homeostatic structural changes of subcellular compartments of rat hippocampal neurons, simultaneously discriminating between excitatory and inhibitory terminals. In addition, we created an automated imaging and analysis pipeline in the opensource bioimage analysis software CellProfiler that identifies and characterizes synaptic puncta from multiplexed images to compare changes in protein levels that occur in excitatory and inhibitory synapses. Using this computational framework, we identified six distinct classes of synapses and found differential regulation of synapsin1 at both excitatory and inhibitory synapses in response to TTX treatment. However, while we found increased inhibitory presynaptic protein levels following activity suppression, TTX treatment did not affect synaptic diversity in $21 \mathrm{~d}$ in vitro (DIV21) neurons. These results broaden our knowledge of the molecular events that occur during synaptic plasticity.

\section{Materials and Methods}

\section{Primary rat neuronal cultures}

Procedures for rat neuronal culture were reviewed and approved for use by the Broad Institutional Animal Care and Use Committee. For hippocampal neuronal cultures, 8-12 Embryonic Day 18 embryos were collected from each pregnant Sprague Dawley rats killed by $\mathrm{CO}_{2}$ (Taconic) processed separately. Embryo hippocampi were dissected in $4^{\circ} \mathrm{C}$ Hibernate $\mathrm{E}$ supplemented with $2 \%$ B27 supplements and $100 \mathrm{U} / \mathrm{ml}$ penicillin/strep (Thermo Fisher Scientific). Hippocampal tissues were digested in Hibernate $\mathrm{E}$ containing $20 \mathrm{U} / \mathrm{ml}$ papain, $1 \mathrm{~mm}$ L-cysteine, $0.5 \mathrm{~mm}$ EDTA (Worthington Biochem), and $0.01 \%$ DNase (Sigma-Aldrich) for $8 \mathrm{~min}$ and stopped with $0.5 \%$ ovomucoid trypsin inhibitor (Worthington Biochem) and $0.5 \%$ bovine serum albumin (BSA; SigmaAldrich). Neurons were plated at a density of 15,000 cells/well onto poly-D-lysine-coated, black-walled, thinbottomed 96-well plates (Greiner Bio-One). Neurons were seeded and maintained in NbActiv1 (BrainBits) at $37^{\circ} \mathrm{C}$ in $95 \%$ air with a $5 \% \mathrm{CO}_{2}$ humidified incubator for $19 \mathrm{~d}$ before use. TTX-treated neurons were treated on 
Table 1: Antibody information

\begin{tabular}{|c|c|c|c|c|c|c|}
\hline Antibody target & Vendor & $\begin{array}{l}\text { Catalog } \\
\text { number }\end{array}$ & $\begin{array}{l}\text { Species and } \\
\text { clonality }\end{array}$ & $\begin{array}{l}\text { Conjugation } \\
\text { strategy }\end{array}$ & $\begin{array}{l}\text { Docking } \\
\text { strand } \\
\text { sequence }\end{array}$ & $\begin{array}{l}\text { Working } \\
\text { concentration } \\
(\mu \mathrm{g} / \mathrm{ml})\end{array}$ \\
\hline PSD-95 & Cell Signaling Technology & 3450 & Rabbit monoclonal & - & - & 0.1 \\
\hline vGAT & Synaptic Systems & 131011 & Mouse monoclonal & SMCC & p3 & 10 \\
\hline Gephyrin & Synaptic Systems & 147208 & Rat chimeric & - & - & 3 \\
\hline MAP2 & Novus Biologicals & NB300-213 & Chicken polyclonal & - & - & \\
\hline Synapsin 1 & Santa Cruz & sc-7379 & Goat polyclonal & SMCC & p9 & 3 \\
\hline SHANK3 & Santa Cruz & sc-30193 & Rabbit polyclonal & SiteClick & p6 & 7.4 \\
\hline Homer-1b/c & Santa Cruz & sc-20807 & Rabbit polyclonal & SMCC & p10 & 4 \\
\hline NR2B & NeuroMab & 75-097 & Mouse monoclonal & - & - & 10 \\
\hline Anti-rabbit secondary & Life Technologies & A16126 & Goat polyclonal & SMCC & p1 & 3 \\
\hline Anti-mouse secondary & Life Technologies & A16068 & Goat polyclonal & SMCC & p12 & 3 \\
\hline $\begin{array}{l}\text { Alexa Fluor } 555 \text { anti- } \\
\text { guinea pig secondary }\end{array}$ & Thermo Fisher & A21435 & Goat polyclonal & - & - & 4 \\
\hline
\end{tabular}

All antibodies and the working concentration used in this study are listed with the company name catalog and conjugation style.

day 19 with $1 \mu \mathrm{M}$ TTX (Tocris Bioscience) for $48 \mathrm{~h}$ then harvested for immunostaining. All procedures involving animals were in accordance with the National Institutes of Health Guide for the Care and Use of Laboratory Animals.

\section{Immunostaining for LNA-PRISM}

Following TTX-treatment cells were fixed in $4 \%$ paraformaldehyde in and $4 \% \mathrm{wt} / \mathrm{vol}$ sucrose in PBS for $15 \mathrm{~min}$ at room temperature and then permeabilized with $0.25 \%$ Triton X-100 in PBS. Permeabilized cells were incubated in $50 \mu \mathrm{g} / \mathrm{ml}$ RNase A (Thermo Fisher Scientific) and 230 $\mathrm{U} / \mathrm{ml}$ RNase T1 (Thermo Fisher Scientific) in PBS at $37^{\circ} \mathrm{C}$ for $1 \mathrm{~h}$ to reduce the fluorescent background caused by ssLNA-RNA binding and subsequently washed three times with PBS. Cells were then blocked for $1 \mathrm{~h}$ at room temperature with $5 \%$ BSA in PBS. The first round of primary staining was performed using unconjugated primary antibodies diluted in the regular blocking buffer: MAP2, VGLUT1, postsynaptic density-95 (PSD-95), NR2B, and gephyrin. Cells were incubated in primary antibodies overnight at $4{ }^{\circ} \mathrm{C}$, washed three times with PBS, and then incubated in the nuclear blocking buffer [5\% BSA and $1 \mathrm{mg} / \mathrm{ml}$ salmon sperm DNA (Sigma-Aldrich) in PBS] for $1 \mathrm{~h}$ at room temperature. The first round of secondary staining antibodies was diluted in the nuclear blocking buffer and incubated for $1 \mathrm{~h}$ at room temperature. Antibodies used in the first round of secondary staining was: goat-anti-chicken-Alexa Fluor 488, goat-anti-guinea pig-Alexa Fluor 555 and goat-anti-rabbit-p1, goat-antimouse-p12, and goat-anti-rat-p7. Cells were washed three times with PBS, postfixed for 15 min with $4 \%$ paraformaldehyde and $4 \% \mathrm{wt} / \mathrm{vol}$ sucrose in PBS. Cells were washed three times with PBS and incubated again in the nuclear blocking buffer for $30 \mathrm{~min}$ at room temperature. The second round of primary antibodies were incubated overnight at $4^{\circ} \mathrm{C}$ in the following primary antibody/peptide solution diluted in the nuclear blocking buffer using: phalloidin-p2, vGAT-p3, cortactin-p4, SHANK3-p6, bassoon-p8, synapsin1-p9, and homer-1b/c-p10. Cells were then washed three times with PBS then DAPI stained for $15 \mathrm{~min}$. See Table 1 for detailed antibody information and antibody conjugation method.

\section{Multiplexed confocal imaging of neurons using LNA- PRISM}

LNA-PRISM imaging was performed using the Opera Phenix High-Content Screening System (PerkinElmer) equipped with a fast laser-based autofocus system, high NA water immersion objective $(63 \times$, numerical aperture $=1.15)$, two large format scientific complementary metal-oxide semiconductor (sCMOS) cameras and spinning disk optics; 405-, 488-, and 561-nm wavelength laser lines were used as excitation for DAPI, MAP2, and vGlut1 channels, respectively. PRISM images were acquired using a $640-\mathrm{nm}$ laser $(40 \mathrm{~mW})$, sCMOS camera with 1- to 2-s exposure time, and effective pixel size of $187 \mathrm{~nm}$. Imaging probe was freshly diluted to $10 \mathrm{~nm}$ in imaging buffer (500 mM NaCl in PBS, pH 8) immediately before imaging. Neurons were incubated with imaging probes for $5 \mathrm{~min}$ and then washed twice with imaging buffer to remove unbound probe. See Table 2 for LNA imager probe sequences. For each field of view, a stack of three images was acquired with an axial step-size of $0.5 \mu \mathrm{m}$. At least five lateral fields of view were imaged per replicate of the six replicates per condition, un-treated and TTX treated. Following each round of imaging, cells were washed two times with wash buffer $(0.01 \times \mathrm{PBS})$ for $3 \mathrm{~min}$ per round.

\section{Image analysis}

CellProfiler (McQuin et al., 2018) is a popular image analysis tool containing numerous image segmentation 
Table 2: Docking strand and imaging probe sequences used in PRISM

\begin{tabular}{|c|c|c|}
\hline $\begin{array}{l}\text { Sequence } \\
\text { name }\end{array}$ & $\begin{array}{l}\text { Docking strand } \\
\text { sequence }\left(5^{\prime} \text { to } 3^{\prime}\right)\end{array}$ & $\begin{array}{l}\text { ssLNA imaging probe } \\
\text { sequence }\left(5^{\prime} \text { to } 3^{\prime}\right)\end{array}$ \\
\hline $\mathrm{p} 1$ & TTATACATCTA & $\mathrm{T}^{\star} \mathrm{AGAT}^{*} \mathrm{G}^{*} \mathrm{TATAA}$ \\
\hline p2 & TTATCTACATA & TATGT $^{\star} A^{*} G^{*}$ ATAA \\
\hline p3 & TTTCTTCATTA & $\mathrm{TAAT}^{*} \mathrm{G}^{*} \mathrm{~A}^{*} \mathrm{AGAAA}$ \\
\hline p4 & TTATGAATCTA & $\mathrm{TA}^{*} \mathrm{GAT}{ }^{*} \mathrm{~T}^{\star} \mathrm{CATAA}$ \\
\hline p5 & Not used in this study & Not used in this study \\
\hline p6 & TTAATTGAGTA & $\mathrm{T}^{\star} \mathrm{A}^{\star} \mathrm{CTCAATTAA}$ \\
\hline p7 & TTAATTAGGAT & $\mathrm{A}^{*} \mathrm{~T}^{\star} \mathrm{CC} \mathrm{T}^{\star} \mathrm{AATTAA}$ \\
\hline p8 & TTATAATGGAT & $A^{*} T^{\star} C^{*}$ ATTATAA \\
\hline p9 & TTTAATAAGGT & $\mathrm{A}^{*} \mathrm{CC}^{*} \mathrm{~T}^{\star}{ }^{*} \mathrm{TATTAA}$ \\
\hline p10 & TTATAGAGAAG & $\mathrm{C}^{\star} \mathrm{T}^{\star} \mathrm{TC}^{\star}{ }^{\mathrm{T}} \mathrm{TCTATA}$ \\
\hline p11 & Not used in this study & Not used in this study \\
\hline p12 & TTATAGTGATT & $\mathrm{A}^{*} \mathrm{ATC}^{*} \mathrm{~A}^{*} \mathrm{CTATAA}$ \\
\hline
\end{tabular}

LNA substitutions are indicated with * following the LNA nucleotide.

methods and analysis tools. The pipeline can be divided into three main stages. In the first stage the images are imported, aligned and uneven illumination is corrected. The output from this first stage of the pipeline is the aligned tiff images with the corrected background. These images serve as a quality control checkpoint to ensure correct image alignment and illumination correction. The second stage of the pipeline performs image segmentation on the images to define and locate the nuclei, dendrites and puncta from each round of imaging. The pipeline offers users the ability to easily customize key aspects of the analysis methodology such as illumination correction and thresholding without any source code modifications. This stage of the pipeline produces binary images of the object segmentation and also the grayscale images of the puncta channels following application of the white-top hat filters used to enhance puncta segmentation. These images serve as helpful guides to ensure optimal image segmentation. The final stage of the pipeline groups all of the segmented objects into synapses, based on the level of overlap with the synapsin 1 objects, nuclear masks and the dendritic masks. For our analysis puncta were considered non-synaptic if the puncta overlapped the nuclei region, were outside of the dendrite object masks or did not overlap with synapsin1. Postsynaptic objects with at least $6.25 \%$ overlap with synapsin 1 were considered synaptic. Presynaptic objects were considered synaptic if the overlap was at least $50 \%$. The final stage of the pipeline outputs binary images of the synaptic objects and multiple csv files containing the quantification of the synaptic objects (Extended Data Fig. 1-2). For thresholding, the RobustBackground method was used to choose a threshold value for each synaptic target. This method was first applied to all images corresponding to the untreated group. The resulting threshold values were then averaged to produce a single threshold for each target, which was applied to both the untreated and TTX-treated group to ensure that all images were segmented identically. Only puncta with equivalent diameters between 3 and 15 pixels were included in the analysis. The equivalent diameter is the is the diameter of a circle with the same area as the measured object. Synapses were defined as excitatory when only vGlut1 puncta were present and as inhibitory when only vGAT puncta were present. For quality control of clustering, we isolated and plotted synapses from individual replicates separately to ensure identified clusters were not artifacts resulting from differences in staining or image intensity among the image sets (Extended Data Fig. 5-1).

\section{PRISM antibody validation}

Conjugation of antibodies and peptides with ssDNA may alter antibody affinity and specificity. In order to confirm that ssDNA-conjugated antibodies and peptides were unperturbed by conjugation, extensive validation was performed for each synaptic and cytoskeletal target. Specifically, for each target a mixture containing both conjugated and unconjugated antibodies was applied to neuronal samples to verify that staining patterns of the unconjugated and conjugated antibodies were the same.

\section{Code accessibility}

The automated CellProfiler synaptic protein analysis pipeline is available as Extended Data 1.

\section{Statistical analysis}

All data are presented using their mean $\pm 95 \%$ confidence interval with $N=6$ independent neuronal culture replicates for untreated and $N=6$ neuronal culture replicates for TTX-treated samples. The mean intensity of each experimental condition was normalized to the mean intensity of the untreated wells within the respective plate. For each individual replicate, five to nine images were collected. To ensure consistent, uniform data collection across each of the 6 imaged replicates corresponding to each treatment condition, 2000 individual synapses were randomly subsampled from each replicate and combined in the final dataset to ensure that each replicate contributed equally to the final results. During imaging, a mechanical failure occurred while imaging one of the TTXtreated replicates so that it was necessary to eliminate this replicate from the final dataset, resulting in $N=6$ untreated and $N=5 T T X$-treated samples including in the final data and statistical analyses. All statistical analysis was performed using $R$ statistical environment. Two-tailed permutation $t$ tests were performed by calculating the mean difference from 5000 reshuffles of the untreated and TTXtreated samples. The $p$ values represent the likelihood of observing the reported effect size, if the null hypothesis of zero difference is true. For all data where $t$ test was performed effect size was also calculated using effsize $R$ package (Torchiano, 2016). Effect size confidence intervals were calculated using random resampling $(n=5000)$ of mean integrated intensity measurements from each replicate $(n=6.5$; untreated, TTX) using boot package in R (Davison and Hinkley, 1997). All confidence intervals are bias-corrected and accelerated. Plots created using ggridges package in $\mathrm{R}$ (Wilke, 2018). Power analysis performed using pwr.t2n.test in pwr package in $\mathrm{R}$ (Champely, 2020). Barplots were created using ggplot2 and ggpubr packages in R (Wickham, 2016; Kassambara, 2019). Uniform manifold approximation and projection (UMAP) was performed using the umap 
Table 3: Specific features from CellProfiler used as input for UMAP

\begin{tabular}{|c|c|c|}
\hline Metric & $\begin{array}{l}\text { Region of } \\
\text { interest } \\
\text { source }\end{array}$ & $\begin{array}{l}\text { Target used for } \\
\text { measurement }\end{array}$ \\
\hline Compactness & Synapsin1 & Synapsin1 \\
\hline Eccentricity & Synapsin1 & Synapsin 1 \\
\hline Euler number & Synapsin1 & Synapsin1 \\
\hline Extent & Synapsin1 & Synapsin1 \\
\hline Form factor & Synapsin 1 & Synapsin1 \\
\hline Major axis length & Synapsin1 & Synapsin 1 \\
\hline Maximum radius & Synapsin 1 & Synapsin 1 \\
\hline Mean radius & Synapsin 1 & Synapsin 1 \\
\hline Minor axis length & Synapsin1 & Synapsin 1 \\
\hline Orientation & Synapsin1 & Synapsin1 \\
\hline Perimeter & Synapsin 1 & Synapsin1 \\
\hline Solidity & Synapsin 1 & Synapsin1 \\
\hline Puncta number & Synapsin1 & Homer-1b/c \\
\hline Puncta number & Synapsin 1 & NR2B \\
\hline Puncta number & Synapsin1 & PSD-95 \\
\hline Puncta number & Synapsin 1 & SHANK3 \\
\hline Puncta number & Synapsin 1 & Actin \\
\hline Puncta number & Synapsin1 & Cortactin \\
\hline Puncta number & Synapsin1 & vGlut-1 \\
\hline Integrated intensity edge & Synapsin1 & DAPI \\
\hline Integrated intensity edge & Synapsin1 & Gephyrin \\
\hline Integrated intensity & Synapsin 1 & NR2B \\
\hline Integrated intensity & Synapsin1 & PSD-95 \\
\hline Integrated intensity & Synapsin 1 & SHANK3 \\
\hline Integrated intensity & Synapsin 1 & Actin \\
\hline Integrated intensity & Synapsin1 & Synapsin1 \\
\hline Integrated intensity & Synapsin 1 & vGlut-1 \\
\hline Lower quartile intensity & Synapsin1 & Synapsin1 \\
\hline MAD intensity & Synapsin1 & DAPI \\
\hline MAD intensity & Synapsin 1 & Gephyrin \\
\hline MAD intensity & Synapsin1 & Homer-1b/c \\
\hline MAD intensity & Synapsin1 & MAP2 \\
\hline MAD intensity & Synapsin 1 & PSD-95 \\
\hline MAD intensity & Synapsin1 & SHANK3 \\
\hline MAD intensity & Synapsin1 & Actin \\
\hline MAD intensity & Synapsin1 & Bassoon \\
\hline MAD intensity & Synapsin1 & Cortactin \\
\hline MAD intensity & Synapsin1 & Synapsin1 \\
\hline MAD intensity & Synapsin 1 & vGAT \\
\hline Mass displacement & Synapsin1 & DAPI \\
\hline Mass displacement & Synapsin1 & Gephyrin \\
\hline Mass displacement & Synapsin 1 & Homer-1b/c \\
\hline Mass displacement & Synapsin 1 & MAP2 \\
\hline Mass displacement & Synapsin1 & NR2B \\
\hline Mass displacement & Synapsin 1 & PSD-95 \\
\hline Mass displacement & Synapsin1 & SHANK3 \\
\hline Mass displacement & Synapsin1 & Actin \\
\hline Mass displacement & Synapsin1 & Bassoon \\
\hline Mass displacement & Synapsin 1 & Cortactin \\
\hline Mass displacement & Synapsin 1 & Synapsin1 \\
\hline Mass displacement & Synapsin 1 & vGlut-1 \\
\hline Mass displacement & Synapsin 1 & vGAT \\
\hline Min intensity edge & Synapsin1 & Homer-1b/c \\
\hline Min intensity edge & Synapsin1 & NR2B \\
\hline Min intensity edge & Synapsin 1 & PSD-95 \\
\hline Min intensity edge & Synapsin 1 & SHANK3 \\
\hline Min intensity edge & Synapsin1 & Actin \\
\hline Min intensity edge & Synapsin 1 & Bassoon \\
\hline Min intensity edge & $\begin{array}{l}\text { Synapsin1 } \\
\text { (Continued) }\end{array}$ & Cortactin \\
\hline
\end{tabular}

Table 3: Continued

\begin{tabular}{|c|c|c|}
\hline Metric & $\begin{array}{l}\text { Region of } \\
\text { interest } \\
\text { source }\end{array}$ & $\begin{array}{l}\text { Target used for } \\
\text { measurement }\end{array}$ \\
\hline$\overline{\text { Min intensity edge }}$ & Synapsin1 & vGlut-1 \\
\hline Min intensity & Synapsin 1 & Gephyrin \\
\hline Min intensity & Synapsin1 & MAP2 \\
\hline Min intensity & Synapsin 1 & Synapsin1 \\
\hline Min intensity & Synapsin 1 & vGAT \\
\hline Std intensity & Synapsin 1 & Gephyrin \\
\hline Std intensity & Synapsin1 & NR2B \\
\hline Std intensity & Synapsin1 & vGlut-1 \\
\hline Upper quartile intensity & Synapsin1 & DAPI \\
\hline Distance (centroid) & Gephyrin & Gephyrin \\
\hline Integrated intensity & Gephyrin & Gephyrin \\
\hline Mass displacement & Gephyrin & Gephyrin \\
\hline Std intensity & Gephyrin & Gephyrin \\
\hline Distance (centroid) & Homer-1b/c & Homer-1b/c \\
\hline Integrated intensity & Homer-1b/c & Homer-1b/c \\
\hline MAD intensity & Homer-1b/c & Homer-1b/c \\
\hline Mass displacement & Homer-1b/c & Homer-1b/c \\
\hline Min intensity edge & Homer-1b/c & Homer-1b/c \\
\hline Distance (minimum) & NR2B & NR2B \\
\hline Integrated intensity & NR2B & NR2B \\
\hline MAD intensity & NR2B & NR2B \\
\hline Mass dissplacement & NR2B & NR2B \\
\hline Distance (minimum) & PSD-95 & PSD-95 \\
\hline Integrated intensity & PSD-95 & PSD-95 \\
\hline MAD intensity & PSD-95 & PSD-95 \\
\hline Mass displacement & PSD-95 & PSD-95 \\
\hline Min intensity & PSD-95 & PSD-95 \\
\hline Distance (minimum) & SHANK3 & SHANK3 \\
\hline Integrated intensity & SHANK3 & SHANK3 \\
\hline MAD intensity & SHANK3 & SHANK3 \\
\hline Mass displacement & Actin & Actin \\
\hline Distance (centroid) & Actin & Actin \\
\hline Integrated intensity & Actin & Actin \\
\hline MAD intensity & Actin & Actin \\
\hline Mass displacement & Actin & Actin \\
\hline Distance (centroid) & Bassoon & Bassoon \\
\hline MAD intensity & Bassoon & Bassoon \\
\hline Mass displacement & Bassoon & Bassoon \\
\hline Distance (centroid) & Cortactin & Cortactin \\
\hline Integrated intensity & Cortactin & Cortactin \\
\hline MAD intensity & Cortactin & Cortactin \\
\hline Mass displacement & Cortactin & Cortactin \\
\hline Min intensity & Cortactin & Cortactin \\
\hline MAD intensity & vGlut-1 & vGlut-1 \\
\hline Mass displacement & vGlut-1 & vGlut-1 \\
\hline Min intensity edge & vGlut-1 & vGlut-1 \\
\hline Mass displacement & vGAT & vGAT \\
\hline Min intensity & vGAT & vGAT \\
\hline Std intensity edge & vGAT & vGAT \\
\hline
\end{tabular}

The region of interest source is the image that was used to create the regions of interest (the puncta objects). The target used for measurement is the image source that the region of interest was used on. For example, synapsin1 puncta (regions of interest) are always created from synapsin1 images, but measurements using those regions can come from any image source, i.e., we can examine what the signal of vGlut-1, homer $1 \mathrm{~b} / \mathrm{c}$, etc. is within the regions created by the synapsin 1 objects.

package in $\mathrm{R}$ stats (Konopka, 2019). Columns containing missing data (NA) were removed. Feature reduction was performed using findCorrelation in caret package of $R$ stats (Wing et al., 2019). The remaining columns following feature 
A

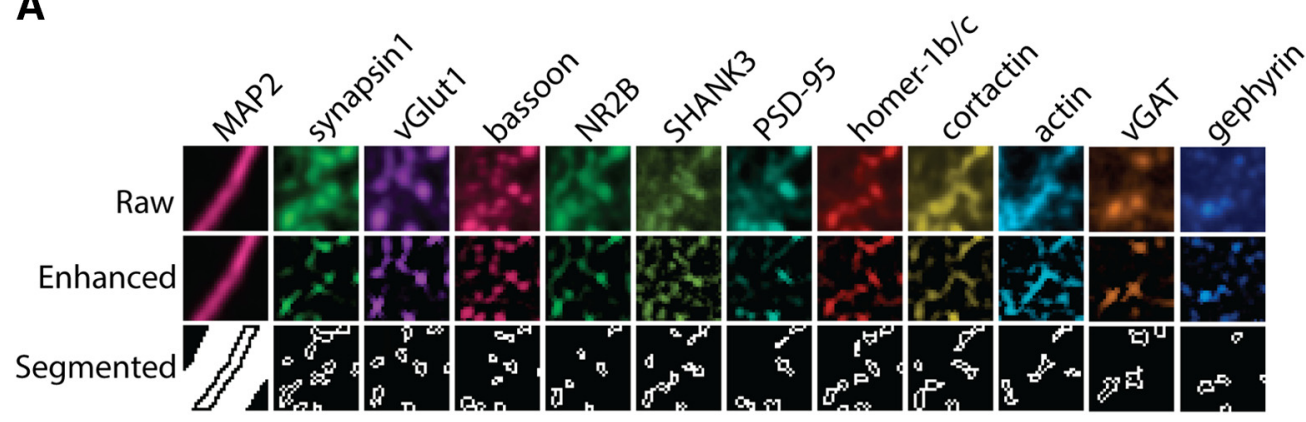

B
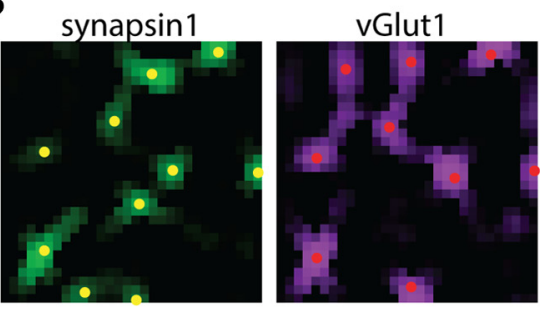

C
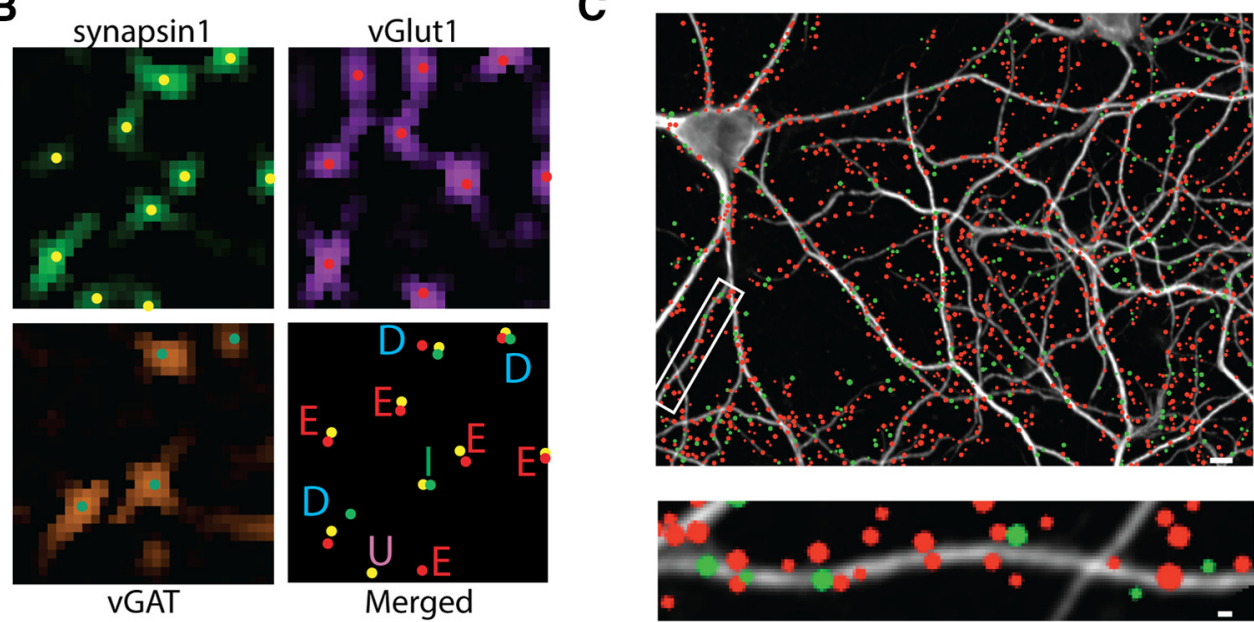

Figure 1. Measuring synaptic content from excitatory and inhibitory synapses using CellProfiler. A, Multiplexed images of PRISM stained DIV21 hippocampal neurons are used as input for the CellProfiler pipeline. Raw images (top) are aligned using MAP2 signal. A white-top filter is applied to enhance puncta (middle). Puncta are thresholded and separated into individual puncta using peak intensity (bottom). B, Synapses are labeled excitatory (E) or inhibitory (I) using the presence or absence of excitatory-specific (vGlut1) or inhibitory-specific (vGAT) markers. Synapses with both markers are labeled as dual (D). Clusters that do not contain either marker are labeled as unknown (U). C, Representative image (top) and enlarged dendrite (bottom) from a MAP2-stained DIV21 hippocampal neuron with excitatory (red) and inhibitory (green) synapses labeled as colored circles. The size of the colored circle represents the relative synapsin1 area. Scale bar: $1 \mu \mathrm{m}$.

reduction are listed in Table 3. Remaining data were centered using the scale function of $\mathrm{R}$ Stats before using the data as input for UMAP. The resulting UMAP object was used to transform all remaining data. Hierarchical densitybased spatial clustering of applications with noise (HDBSCAN) was performed on umap output using hdbscan module from python with min_cluster_size $=100$ (Mclnnes et al., 2017). Data considered as noise from HDBSCAN was removed from the plot. Scatterplots were generated using ggplot2 and ggpubr. Heatmaps were created using gplots R package (Warnes et al., 2020). Individual correlation matrices were generated for each biological replicate within each UMAP group and then averaged to produce a final representative correlation matrix for each UMAP group. Correlation values between -0.4 and 0.4 obscured to highlight strong correlations.

\section{Results}

\section{Characterization of synaptic content from multiplexed images}

We designed a Cell Profiler pipeline to automate synapse detection and protein analysis. Analysis of individual synapses from multiplexed images requires three main computational steps: image alignment, synapse segmentation, and synapse alignment. To address these technical requirements, we generated a CellProfiler pipeline that imports multiplexed images (four single-channel images from a single field), aligns images from ten different imaging rounds of four channels using MAP2 staining, and uses the synapsin1 channel for synapse identification. Puncta signals are enhanced using a white top-hat filter and then segmented using intensity peaks (Fig. 1A; Extended Data Fig. 1-1). Following segmentation, each individual punctum from each channel is then assigned to a synapsin1 cluster, depending on the percentage of overlap with the synapsin1 signal (see Materials and Methods). Thus, our "synapses" are a conglomeration of puncta: a single synapsin1 punctum and the collection of individual puncta from the other channels that overlap with that synapsin1 cluster. A large number of geometric and intensity feature calculations are then performed to enable a comprehensive and detailed phenotypic analysis (Extended Data Fig. 1-2). Specifically, we measured multiple intensity and shape features for each punctum to later identify synaptic clusters. 


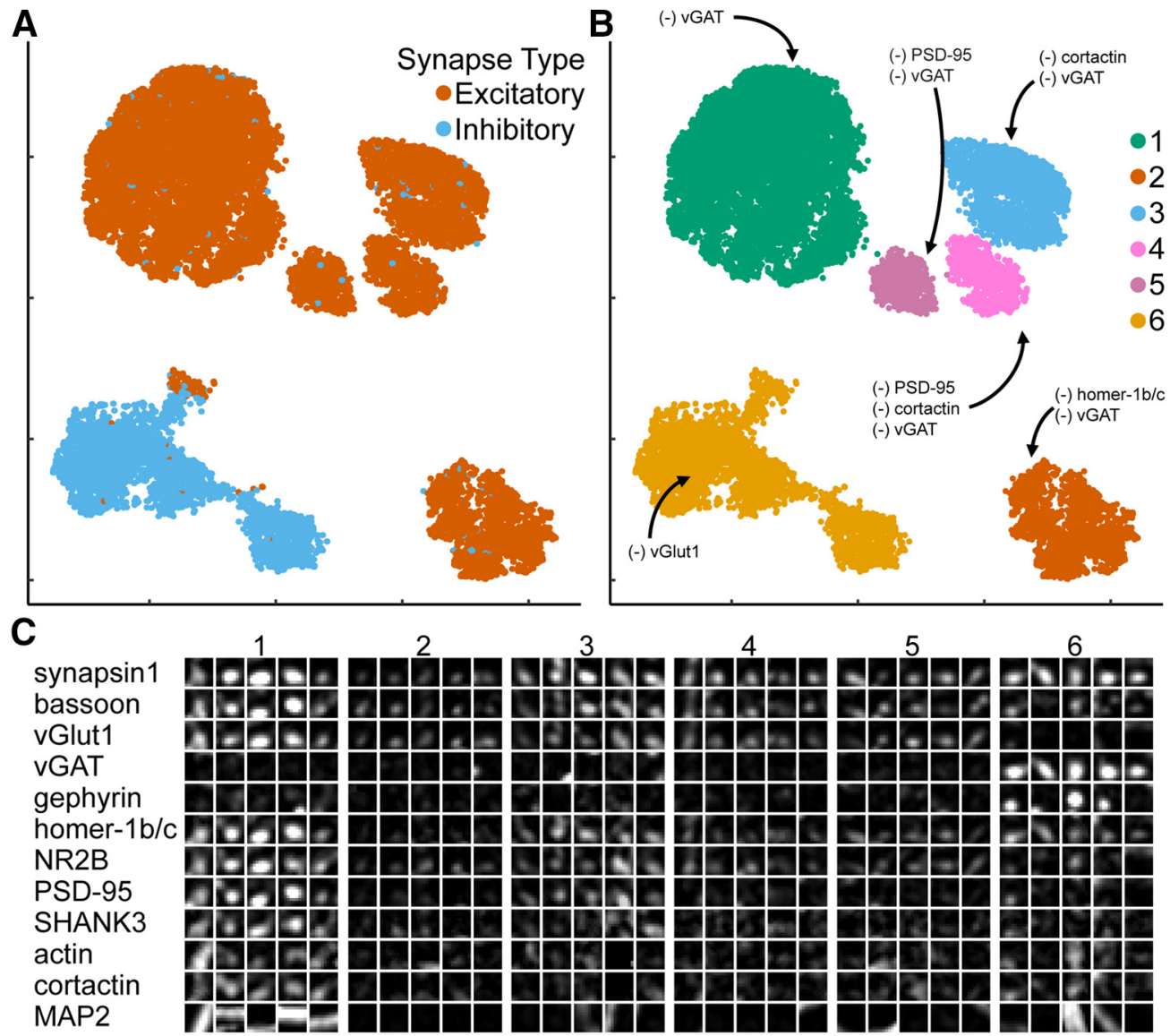

D

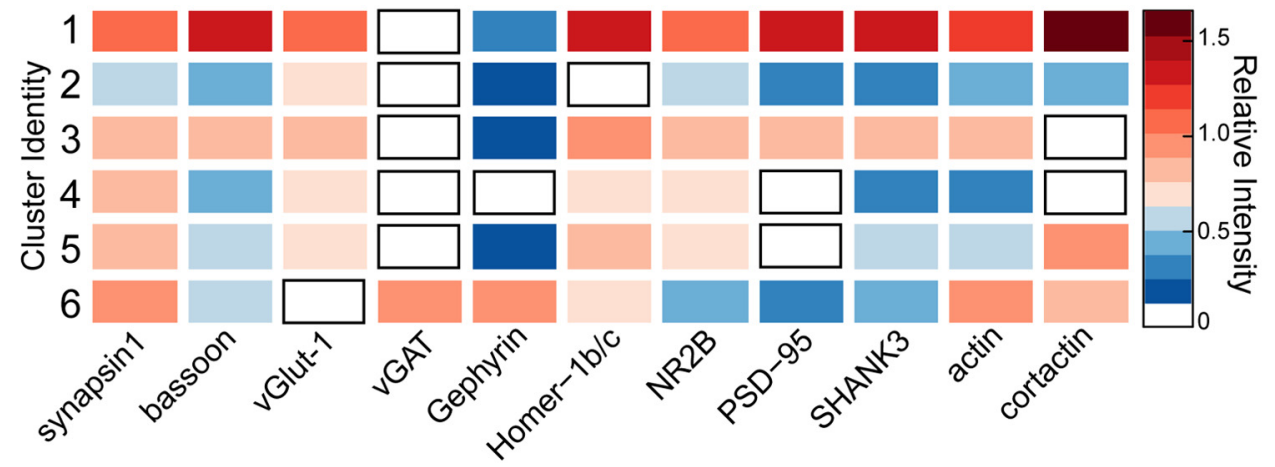

Figure 2. Synaptic cluster identification using UMAP. A, UMAP plots of individual synapses $(n=10,000)$ using CellProfiler output separates excitatory (red) and inhibitory (blue) synapses into two major clusters with multiple subclusters. $\boldsymbol{B}$, Unique clusters identified by HDBSCAN. (-) indicates synaptic target below limit of detection. $\boldsymbol{C}$, Representative synapses from each cluster. $\boldsymbol{D}$, Heatmap indicates the average relative intensities for each synaptic target within each cluster. All values are normalized to untreated mean integrated intensity.

Primary rat hippocampal neurons were grown for $19 \mathrm{~d}$ in culture, then fixed and stained with our PRISM antibodies/peptides: PSD-95, synapsin1, bassoon, actin, cortactin, homer-1b/c, SHANK3, NR2B, and vGlut1 plus two antibodies against inhibitory synaptic proteins, vGAT and gephyrin (Fig. 1A). Synapses were defined as excitatory when the presynaptic proteins synapsin 1 and vGlut 1 were present versus inhibitory when synapsin 1 and vGAT were present (Fig. 1C,D). Under this classification criterion, $66 \%$ of detected puncta were defined as synapses and used for further characterization (Extended Data Fig. 1-3). Synapses that failed to meet our criteria of classification for glutamatergic or GABAergic synapses were excluded from the analysis. These types of puncta were labeled as unclassified (Extended Data Fig. 1-3) because they either lacked vGlut1 or vGAT ( $\sim 22 \%$, "unknown"), or contained both synaptic markers ( $12 \%$, "dual"). Thus, the CellProfiler pipeline enabled us to restrict our analysis of synaptic composition to synapses we could confidently identify. 


\section{Characterization of synapse diversity}

To characterize synaptic diversity in hippocampal cultured neurons, UMAP was applied to a subset of the CellProfiler pipeline output (Fig. 2A). In total, 15 separate intensity measurements, 14 separate punctum shape measurements, quantification of punctum distances to synapsin1, and quantification of the number of puncta associated with each synapse were measured using CellProfiler (Extended Data Fig. 1-2). Feature reduction (see Materials and Methods) was used to isolate the most important features before clustering. The UMAP output shows clearly distinct excitatory and inhibitory synapses, which were found at a ratio of 5 excitatory to 1 inhibitory, consistent with the ratio observed using the CellProfiler pipeline to classify synapses (Fig. 2A). Most (98.9\%) of the synapses present in the excitatory clusters were positive for vGlut1, staining whereas only $1.1 \%$ of the synapses in those clusters contained vGAT. Similarly, $97.3 \%$ of synapses present in the inhibitory cluster contained synapsin 1 and VGAT and only $2.7 \%$ of these synapses contained synapsin 1 and vGlut1.

To evaluate the quality of the segmentation, we assessed whether canonical proteins specific to one type of synapse were present at excitatory and inhibitory synapses. We found the majority $(78.8 \%)$ of the excitatory synapses did not contain the inhibitory target gephyrin and those that did express gephyrin had lower synaptic levels compared with inhibitory synapses (Table 1, a). Moreover, synapsin1 and gephyrin were further apart (mean distance $1.22 \pm 0.02$ pixels) than synapsin 1 and the excitatory marker PSD-95 (0.92 \pm 0.01 pixels), suggesting the detected gephyrin was likely outside of these excitatory synapses, but overlapping because of limited spatial resolution. Similarly, the excitatory marker PSD-95 was detectable in $35.7 \%$ of inhibitory synapses; however, synaptic levels of PSD-95 within the inhibitory cluster were reduced (Table 1, a) and the mean distance between synapsin1 and PSD-95 (1.5 \pm 0.04 pixels) was almost twice that of synapsin 1 and gephyrin $(0.8 \pm 0.02$ pixels). Thus, given the limits of the imaging resolution and density of the neuronal culture, the image segmentation may have incorrectly assigned proteins to some synapses; however, the assignment of proteins to synapses can be further refined, as needed, using features such as protein levels and distance to synapsin1.

We examined the UMAP output in further detail to identify and characterize synapses with distinct protein expression profiles. Using HDBSCAN applied to the UMAP output, we identified six unique clusters of synaptic subtypes (Fig. 2B,C). Subsequently, we generated heatmaps (Fig. 2D) and additional scatterplots (Extended Data Figs. $2-1,2-2,2-3,2-4,2-5,2-6,2-7,2-8,2-9,2-10,2-11$, $2-12,2-13)$ to distinguish differences among these clusters. Based on the relative vGlut1 and vGAT levels, excitatory synapses correspond to Clusters $1-5$ and inhibitory synapses are contained in Cluster 6 . Cluster 1 was the largest cluster with $57.9 \%$ of the excitatory synapses and had the highest levels of synaptic proteins for all targets relative to the other excitatory clusters (Fig. 2D; Extended Data Fig. 2-14). Compared with Cluster 1, Clusters 2-5 contain lower levels of all synaptic proteins and each of these clusters had very low levels of one or more postsynaptic scaffolding or cytoskeletal protein. To investigate in more detail the differences among the excitatory synaptic clusters and identify the distinguishing features for each synapse subtype, we measured the protein intensity profiles, correlation coefficients, and performed hierarchical clustering for each of the individual clusters (Fig. 3).

Ridgeline plots (Fig. 3, left subpanel) were created for each protein within each cluster to compare the relative synaptic levels of each target and to examine the proportion of synapses with detectable $(>0)$ levels of each target. Additionally, pairwise correlation analysis of the synaptic protein levels was performed to identify proteins with coordinated synaptic expression (Fig. 3, right subpanel). Hierarchical clustering was then performed on the correlation matrix to identify which groups of proteins had similar levels of coordinated synaptic expression. Comparing these features across the excitatory clusters shows that Cluster 1 had the highest level of synaptic proteins, the lowest proportion of synapses with undetectable levels of synaptic proteins (Fig. $3 A-E$, left subpanel), and the most proteins with coordinated synaptic expression (Fig. 3A-E, right subpanel) of the excitatory synaptic clusters. Cluster three was the most similar to Cluster 1 as it had the next highest synaptic levels of proteins and the next highest number of proteins with coordinated synaptic expression. Clusters 2, 4, and 5 had lower levels of proteins at synapses compared with Clusters 1 and 3 , more synapses with undetectable levels of proteins, and very few proteins with coordinated synaptic expression. In these clusters the proteins with most of the coordinated synaptic expression were synapsin 1 and vGlut1. Taken together, these clusters may be synapses in various stages of maturation, synapses actively remodeling or they could represent false synapses caused from staining artifacts.

Cluster 6 contains inhibitory synapses with vGAT detectable in $97.8 \%$ of these synapses. Gephyrin levels were also the highest within this cluster relative to all other clusters, but, interestingly, were only detectable in $61 \%$ of these synapses. The excitatory postsynaptic scaffolds SHANK3 and PSD-95 were assigned to inhibitory synapses in $\sim 41 \%$ and $36 \%$ of the synapses in this cluster. Additionally, homer-1b/c was also found near inhibitory synapses in $73 \%$ of these synapses but with lower intensity with respect to Cluster 1 (Fig. 3; Extended Data Fig. 2-14; Table 4, a). Correlation analysis of proteins within this cluster revealed coordinated synaptic expression between vGAT and synapsin1, between PSD-95 and SHANK3, between homer-1b/c and bassoon and surprisingly between synapsin 1 and homer- $1 \mathrm{~b} / \mathrm{c}$. Taken together, within this cluster, we only see coordinate synaptic expression among the presynaptic inhibitory synaptic proteins. Additionally, our results suggest homer-1b/c may serve some yet unknown function at inhibitory synapses. 

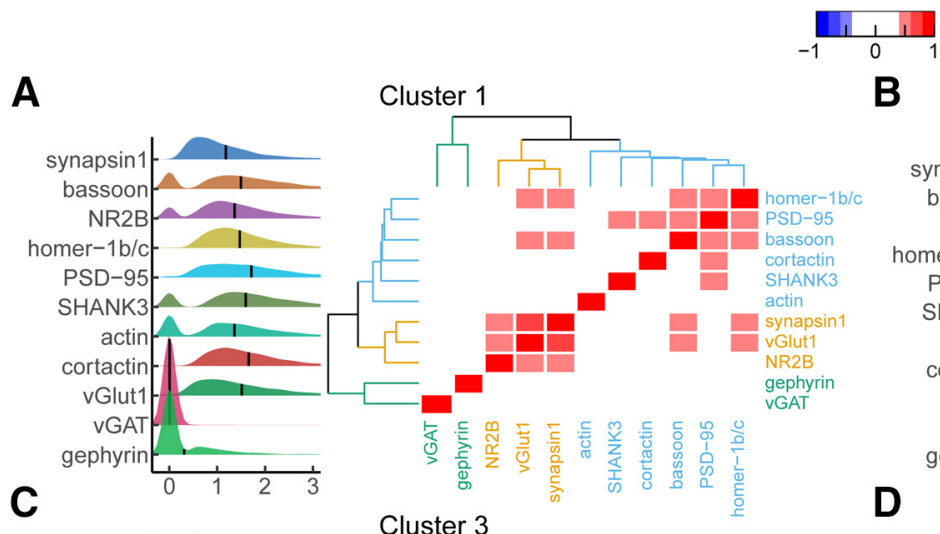

B

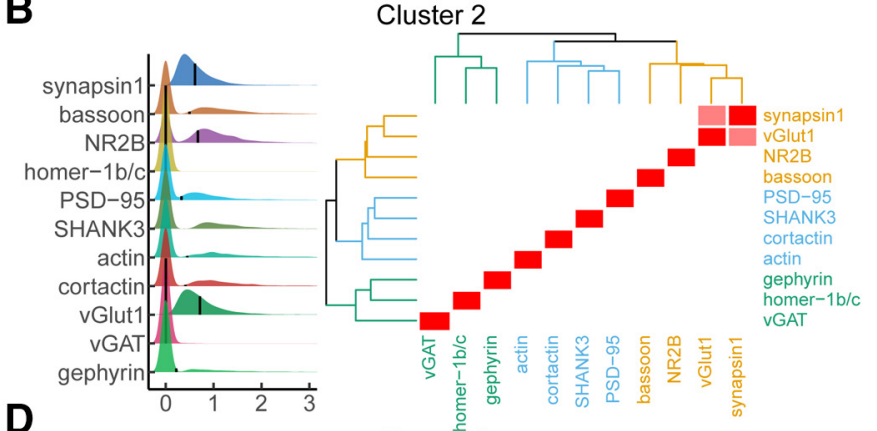

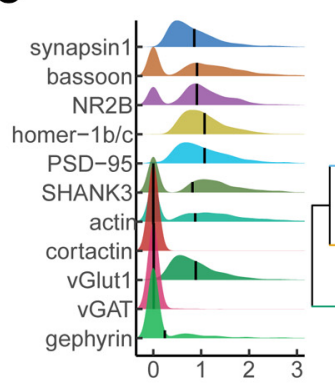

E

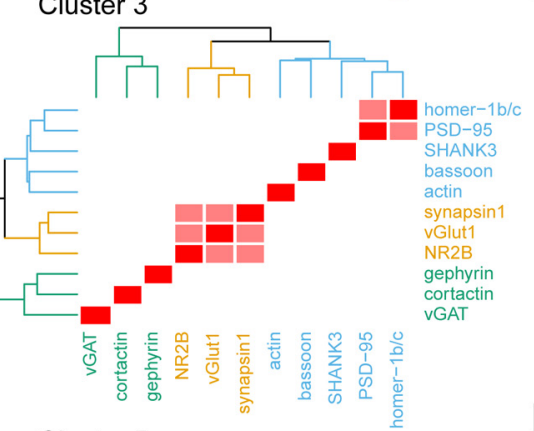

$\mathbf{F}$

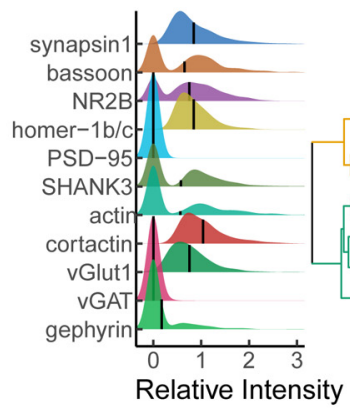

Cluster 5

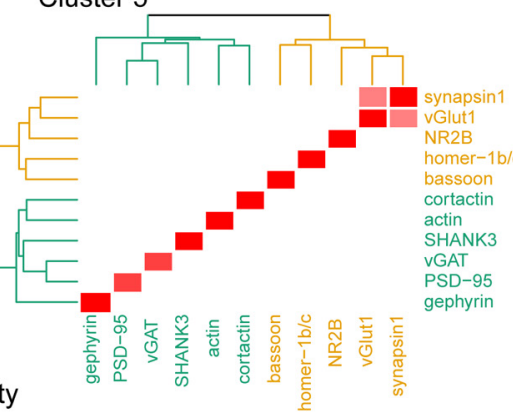

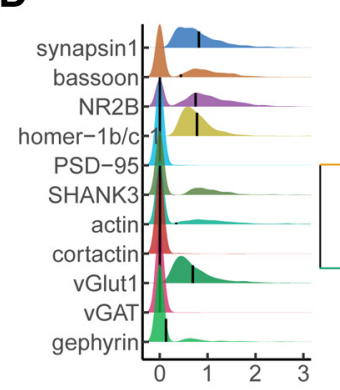

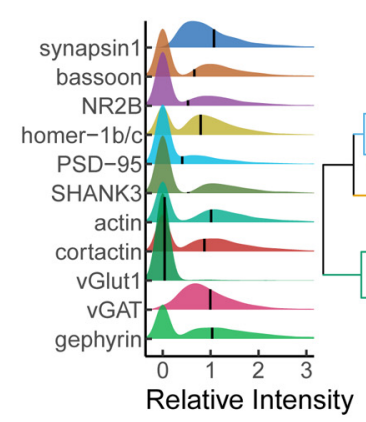

Cluster 4

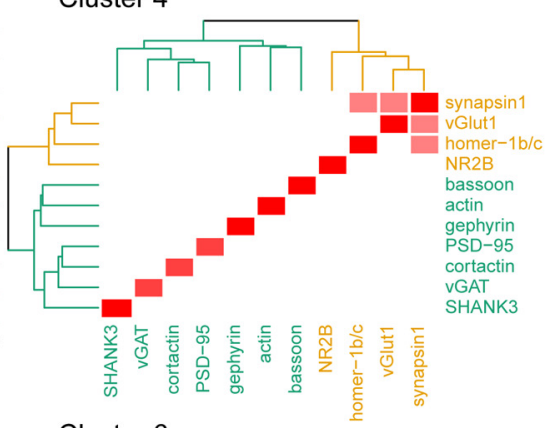

Cluster 6

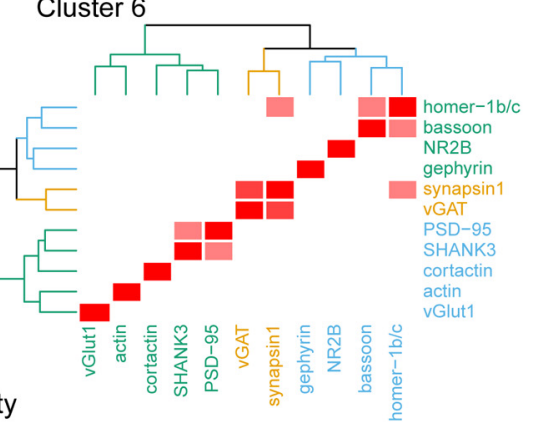

Figure 3. Comparison of synaptic intensity and protein relationships among all proteins within each cluster. Ridgeline plots of relative synaptic intensity for each cluster group $(\boldsymbol{A}-\boldsymbol{F})$ using HDBSCAN. Horizontal black line represents cluster mean intensity. All values are normalized to untreated mean integrated intensity. The first peak indicates synapses with integrated intensity of zero. Heatmap indicates the correlation coefficient between each protein. Correlation values between -0.4 and 0.4 obscured to highlight strong correlations. Dendrograms surrounding heatmap show hierarchical clustering of proteins within each cluster.

\section{Response of excitatory and inhibitory synapses to activity blockade}

The phenomena of neurons eliciting compensatory structural changes within synapses to maintain network homeostatic balance in response to chronic activity blockade has been characterized in numerous studies (Turrigiano, 2008). However, the overview of simultaneous changes in inhibitory and excitatory synapses has been limited by conventional immunocytochemistry. We used PRISM staining to simultaneously investigate the effect of chronic activity blockade on excitatory and inhibitory synapses. For this, the distribution pattern of excitatory and inhibitory synapses was determined by using the classification method established above. We found a higher abundance of excitatory inputs compared with inhibitory on cultured neurons (Fig. 4B). Under control conditions, glutamatergic synapses have a density of $56 \pm 9.6$ synapses per $100-\mu \mathrm{m}$ length of dendrite, whereas GABAergic synapses density was $15.8 \pm 9.5$ per $100 \mu \mathrm{m}$, which gives an average excitatory to inhibitory synapses ratio of $5 \pm 3: 1$ calculated per replicate (Fig. 4B; Table 4, b). Accordingly with the well-established model that neurons coordinate their excitatory and inhibitory inputs to establish and maintain a constant excitatory-to-inhibitory (E/I) ratio which is essential for circuit function and stability (Zhou et al., 2014; He et al., 2018; He and Cline, 2019), we observed that TTX treatment did not alter this ratio or density of synapses in hippocampal cultured neurons (Fig. 4A,B; Table 4, b).

It is well known that homeostatic plasticity regulates the relative strength of excitatory and inhibitory synapses to keep relatively stable firing rates of neurons by increasing synaptic levels of proteins that regulate excitatory signaling (Turrigiano et al., 1998; Turrigiano and Nelson, 2000, 2004; Liu, 2004; Hartman et al., 2006; Turrigiano, 2008, 2012). We applied our imaging platform and CellProfiler software to identify excitatory and inhibitory synapses 
Table 4: Statistics table

\begin{tabular}{|c|c|c|c|c|c|c|c|c|c|c|c|c|c|c|c|c|c|}
\hline & \multirow[b]{2}{*}{ Figure } & \multirow[b]{2}{*}{ Target } & \multirow[b]{2}{*}{ Group comparison } & \multirow[b]{2}{*}{$\begin{array}{l}\text { Data } \\
\text { structure }\end{array}$} & \multirow[b]{2}{*}{ Type of test } & \multirow[b]{2}{*}{ Shuffles } & \multirow[b]{2}{*}{$p$ value } & \multicolumn{3}{|l|}{ Mean } & \multicolumn{3}{|c|}{ Effect (Cohen's d) } & \multirow[b]{2}{*}{ Power } & \multirow[b]{2}{*}{$p<0.05$} & \multirow{2}{*}{$\begin{array}{l}N \\
\text { UT } \\
\end{array}$} & \multirow[b]{2}{*}{ TTX } \\
\hline & & & & & & & & Difference & $\begin{array}{l}95 \% \mathrm{Cl} \\
\text { lower }\end{array}$ & $\begin{array}{l}95 \% \mathrm{Cl} \\
\text { upper }\end{array}$ & Effect & $\begin{array}{l}95 \% \mathrm{Cl} \\
\text { lower }\end{array}$ & $\begin{array}{l}95 \% \mathrm{Cl} \\
\text { upper }\end{array}$ & & & & \\
\hline \multirow[t]{5}{*}{ a } & & $\begin{array}{c}\text { Gephyrin distance } \\
\text { to synapsin } 1\end{array}$ & $\begin{array}{l}\text { Gephyrin positive } \\
\text { synapses } \\
\text { (UMAP 6 vs } \\
\text { UMAP1-5) }\end{array}$ & Normal & $\begin{array}{l}\text { Permutation } \\
t \text { test }\end{array}$ & 5000 & 0.002 & -0.44 & -0.46 & -0.40 & -16.60 & -20.65 & -12.49 & 1.0 & * & 6 & 5 \\
\hline & $3 A, F$ & $\begin{array}{l}\text { Gephyrin inte- } \\
\text { grated intensity }\end{array}$ & $\begin{array}{l}\text { Gephyrin positive } \\
\text { synapses } \\
\text { (UMAP 6 vs } \\
\text { UMAP1-5) }\end{array}$ & Normal & $\begin{array}{l}\text { Permutation } \\
\quad t \text { test }\end{array}$ & 5000 & 0.002 & 0.35 & 0.20 & 0.49 & 2.70 & 1.25 & 5.46 & 1.0 & * & 6 & 5 \\
\hline & & $\begin{array}{l}\text { PSD-95 distance } \\
\text { to synapsin1 }\end{array}$ & $\begin{array}{l}\text { PSD-95 positive } \\
\text { synapses } \\
\text { (UMAP6 vs } \\
\text { UMAP1-5) }\end{array}$ & Normal & $\begin{array}{l}\text { Permutation } \\
t \text { test }\end{array}$ & 5000 & 0.003 & -0.56 & -0.70 & -0.47 & -5.67 & -7.51 & -4.11 & 1.0 & * & 6 & 5 \\
\hline & $3 A, F$ & $\begin{array}{l}\text { PSD-95 integrated } \\
\text { intensity }\end{array}$ & $\begin{array}{l}\text { PSD-95 positive } \\
\text { synapses } \\
\text { (UMAP6 vs } \\
\text { UMAP1-5) }\end{array}$ & Normal & $\begin{array}{l}\text { Permutation } \\
t \text { test }\end{array}$ & 5000 & 0.007 & -0.23 & -0.31 & -0.10 & -2.56 & -6.14 & -0.69 & 1.0 & * & 6 & 5 \\
\hline & $3 A, F$ & $\begin{array}{l}\text { Homer1-b/c inte- } \\
\text { grated intensity }\end{array}$ & $\begin{array}{l}\text { Homer1-b/c posi- } \\
\text { tive synapses } \\
\text { (UMAP6 vs } \\
\text { UMAP1) }\end{array}$ & Normal & $\begin{array}{l}\text { Permutation } \\
t \text { test }\end{array}$ & 5000 & 0.003 & -0.56 & -0.67 & -0.43 & -5.08 & -7.32 & -3.58 & 1.0 & * & 6 & 5 \\
\hline \multirow[t]{3}{*}{ b } & $4 A$ & $\begin{array}{l}\text { Excitatory synapse } \\
\text { number }\end{array}$ & Untreated vs TTX & Normal & $\begin{array}{l}\text { Permutation } \\
t \text { test }\end{array}$ & 5000 & 0.626 & 2.99 & -7.40 & 15.23 & 0.29 & -1.10 & 1.59 & 0.1 & & 6 & 6 \\
\hline & & $\begin{array}{l}\text { Inhibitory synapse } \\
\text { number }\end{array}$ & Untreated vs TTX & Normal & $\begin{array}{l}\text { Permutation } \\
t \text { test }\end{array}$ & 5000 & 0.592 & 3.62 & -7.56 & 16.24 & 0.33 & -1.03 & 1.69 & 0.1 & & 6 & 6 \\
\hline & $4 B$ & $\begin{array}{l}\text { Excitatory:inhibi- } \\
\text { tory synapse } \\
\text { ratio }\end{array}$ & Untreated vs TTX & Normal & $\begin{array}{l}\text { Permutation } \\
\quad t \text { test }\end{array}$ & 5000 & 0.592 & -0.86 & -4.03 & 1.78 & -0.32 & -1.64 & 1.13 & 0.1 & & 6 & 6 \\
\hline \multirow[t]{11}{*}{ c } & $4 C$ & $\begin{array}{l}\text { vGlut1 integrated } \\
\text { intensity }\end{array}$ & $\begin{array}{l}\text { Untreated vs TTX } \\
\text { (excitatory } \\
\text { synapses) }\end{array}$ & Normal & $\begin{array}{l}\text { Permutation } \\
\quad t \text { test }\end{array}$ & 5000 & 0.006 & 0.17 & 0.10 & 0.24 & 2.82 & 1.17 & 5.03 & 1.0 & * & 6 & 5 \\
\hline & & $\begin{array}{l}\text { vGAT integrated } \\
\text { intensity }\end{array}$ & $\begin{array}{l}\text { Untreated vs TTX } \\
\text { (inhibitory } \\
\text { synapses) }\end{array}$ & Normal & $\begin{array}{l}\text { Permutation } \\
t \text { test }\end{array}$ & 5000 & 0.001 & 0.60 & 0.44 & 0.75 & 4.31 & 2.84 & 6.50 & 1.0 & * & 6 & 5 \\
\hline & & $\begin{array}{l}\text { Synapsin1 inte- } \\
\text { grated intensity }\end{array}$ & $\begin{array}{l}\text { Untreated vs TTX } \\
\text { (excitatory } \\
\text { synapses) }\end{array}$ & Normal & $\begin{array}{l}\text { Permutation } \\
\quad t \text { test }\end{array}$ & 5000 & 0.110 & 0.10 & -0.02 & 0.18 & 1.11 & -0.52 & 4.00 & 0.4 & & 6 & 5 \\
\hline & & $\begin{array}{l}\text { Synapsin1 inte- } \\
\text { grated intensity }\end{array}$ & $\begin{array}{l}\text { Untreated vs TTX } \\
\text { (inhibitory } \\
\text { synapses) }\end{array}$ & Normal & $\begin{array}{l}\text { Permutation } \\
t \text { test }\end{array}$ & 5000 & 0.004 & 0.35 & 0.23 & 0.47 & 3.11 & 1.53 & 4.95 & 1.0 & * & 6 & 5 \\
\hline & & $\begin{array}{l}\text { Bassoon inte- } \\
\text { grated intensity }\end{array}$ & $\begin{array}{l}\text { Untreated vs TTX } \\
\text { (excitatory } \\
\text { synapses) }\end{array}$ & Normal & $\begin{array}{l}\text { Permutation } \\
t \text { test }\end{array}$ & 5000 & 0.129 & 0.18 & -0.04 & 0.38 & 1.02 & -0.66 & 2.49 & 0.3 & & 6 & 5 \\
\hline & & $\begin{array}{l}\text { Bassoon inte- } \\
\text { grated intensity }\end{array}$ & $\begin{array}{l}\text { Untreated vs TTX } \\
\text { (inhibitory } \\
\text { synapses) }\end{array}$ & Normal & $\begin{array}{l}\text { Permutation } \\
t \text { test }\end{array}$ & 5000 & 0.360 & 0.11 & -0.12 & 0.32 & 0.57 & -0.98 & 2.07 & 0.1 & & 6 & 5 \\
\hline & & $\begin{array}{l}\text { SHANK3 inte- } \\
\text { grated intensity }\end{array}$ & $\begin{array}{l}\text { Untreated vs TTX } \\
\text { (excitatory } \\
\text { synapses) }\end{array}$ & Normal & $\begin{array}{l}\text { Permutation } \\
t \text { test }\end{array}$ & 5000 & 0.008 & 0.35 & 0.12 & 0.46 & 2.45 & 0.60 & 7.29 & 0.9 & * & 6 & 5 \\
\hline & & $\begin{array}{l}\text { Homer1-b/c inte- } \\
\text { grated intensity }\end{array}$ & $\begin{array}{l}\text { Untreated vs TTX } \\
\text { (excitatory } \\
\text { synapses) }\end{array}$ & Normal & $\begin{array}{l}\text { Permutation } \\
t \text { test }\end{array}$ & 5000 & 0.037 & 0.15 & 0.02 & 0.26 & 1.54 & -0.02 & 3.44 & 0.6 & * & 6 & 5 \\
\hline & & $\begin{array}{l}\text { PSD-95 integrated } \\
\text { intensity }\end{array}$ & $\begin{array}{l}\text { Untreated vs TTX } \\
\text { (excitatory } \\
\text { synapses) }\end{array}$ & Normal & $\begin{array}{l}\text { Permutation } \\
t \text { test }\end{array}$ & 5000 & 0.017 & 0.15 & 0.06 & 0.24 & 1.93 & 0.71 & 3.31 & 0.8 & * & 6 & 5 \\
\hline & & $\begin{array}{l}\text { Gephyrin inte- } \\
\text { grated intensity }\end{array}$ & $\begin{array}{l}\text { Untreated vs TTX } \\
\text { (inhibitory } \\
\text { synapses) }\end{array}$ & Normal & $\begin{array}{l}\text { Permutation } \\
t \text { test }\end{array}$ & 5000 & 0.610 & 0.07 & -0.14 & 0.35 & 0.31 & -1.24 & 1.72 & 0.1 & & 6 & 5 \\
\hline & & $\begin{array}{l}\text { NR2B integrated } \\
\text { intensity }\end{array}$ & $\begin{array}{l}\text { Untreated vs TTX } \\
\text { (excitatory } \\
\text { synapses) }\end{array}$ & Normal & $\begin{array}{l}\text { Permutation } \\
t \text { test }\end{array}$ & 5000 & 0.089 & 0.12 & -0.02 & 0.22 & 1.18 & -0.48 & 3.26 & 0.4 & & 6 & 5 \\
\hline
\end{tabular}


Table 4: Continued

\begin{tabular}{|c|c|c|c|c|c|c|c|c|c|c|c|c|c|c|c|c|}
\hline & & & & & & & Mean & & & Effect (C & ;ohen's $d$ ) & & & & $N$ & \\
\hline Figure & Target & Group comparison & $\begin{array}{l}\text { Data } \\
\text { structure }\end{array}$ & Type of test & Shuffles & $p$ value & Difference & $\begin{array}{l}95 \% \mathrm{Cl} \\
\text { lower }\end{array}$ & $\begin{array}{l}95 \% \mathrm{Cl} \\
\text { upper }\end{array}$ & Effect & $\begin{array}{l}95 \% \mathrm{Cl} \\
\text { lower }\end{array}$ & $\begin{array}{l}95 \% \mathrm{Cl} \\
\text { upper }\end{array}$ & Power & $p<0.05$ & UT & TTX \\
\hline & $\begin{array}{l}\text { Cortactin inte- } \\
\text { grated intensity }\end{array}$ & $\begin{array}{l}\text { Untreated vs TTX } \\
\text { (excitatory } \\
\text { synapses) }\end{array}$ & Normal & $\begin{array}{l}\text { Permutation } \\
t \text { test }\end{array}$ & 5000 & 0.549 & -0.09 & -0.33 & 0.18 & -0.39 & -2.45 & 1.07 & 0.1 & & 6 & 5 \\
\hline & $\begin{array}{l}\text { Cortactin inte- } \\
\text { grated intensity }\end{array}$ & $\begin{array}{l}\text { Untreated vs TTX } \\
\text { (inhibitory } \\
\text { synapses) }\end{array}$ & Normal & $\begin{array}{l}\text { Permutation } \\
t \text { test }\end{array}$ & 5000 & 0.589 & -0.09 & -0.41 & 0.24 & -0.31 & -1.87 & 1.14 & 0.1 & & 6 & 5 \\
\hline & $\begin{array}{l}\text { Actin integrated } \\
\text { intensity }\end{array}$ & $\begin{array}{l}\text { Untreated vs TTX } \\
\text { (excitatory } \\
\text { synapses) }\end{array}$ & Normal & $\begin{array}{l}\text { Permutation } \\
t \text { test }\end{array}$ & 5000 & 0.475 & -0.07 & -0.26 & 0.04 & -0.53 & -1.80 & 1.06 & 0.1 & & 6 & 5 \\
\hline & $\begin{array}{l}\text { Actin integrated } \\
\text { intensity }\end{array}$ & $\begin{array}{l}\text { Untreated vs TTX } \\
\text { (inhibitory } \\
\text { synapses) }\end{array}$ & Normal & $\begin{array}{l}\text { Permutation } \\
t \text { test }\end{array}$ & 5000 & 0.794 & 0.04 & -0.22 & 0.38 & 0.17 & -1.48 & 2.06 & 0.1 & & 6 & 5 \\
\hline \multirow[t]{25}{*}{ d $5 C$} & Synapsin1 UMAP1 & Untreated vs TTX & Normal & $\begin{array}{l}\text { Permutation } \\
t \text { test }\end{array}$ & 5000 & 0.202 & 0.13 & -0.05 & 0.30 & 0.84 & -0.72 & 2.49 & 0.2 & & 5 & \\
\hline & Synapsin1 UMAP2 & Untreated vs TTX & Normal & $\begin{array}{c}\text { Permutation } \\
t \text { test }\end{array}$ & 5000 & 0.479 & -0.03 & -0.12 & 0.03 & -0.47 & -1.83 & 1.09 & 0.1 & & 6 & 5 \\
\hline & Synapsin1 UMAP3 & Untreated vs TTX & Normal & $\begin{array}{c}\text { Permutation } \\
t \text { test }\end{array}$ & 5000 & 0.569 & 0.03 & -0.10 & 0.09 & 0.36 & -1.23 & 3.70 & 0.1 & & 6 & 5 \\
\hline & Synapsin1 UMAP4 & Untreated vs TTX & Normal & $\begin{array}{l}\text { Permutation } \\
\quad t \text { test }\end{array}$ & 5000 & 0.237 & -0.06 & -0.17 & 0.03 & -0.82 & -2.54 & 1.03 & 0.2 & & 6 & 5 \\
\hline & Synapsin1 UMAP5 & Untreated vs TTX & Normal & $\begin{array}{l}\text { Permutation } \\
t \text { test }\end{array}$ & 5000 & 0.099 & -0.09 & -0.18 & 0.01 & -1.09 & -2.63 & 0.48 & 0.4 & & 6 & 5 \\
\hline & Synapsin1 UMAP6 & Untreated vs TTX & Normal & $\begin{array}{l}\text { Permutation } \\
t \text { test }\end{array}$ & 5000 & 0.005 & 0.37 & 0.24 & 0.49 & 3.09 & 1.64 & 4.75 & 1.0 & * & 6 & 5 \\
\hline & Gephyrin UMAP1 & Untreated vs TTX & Normal & $\begin{array}{l}\text { Permutation } \\
t \text { test }\end{array}$ & 5000 & 0.464 & 0.02 & -0.03 & 0.07 & 0.47 & -0.92 & 1.96 & 0.1 & & 6 & 5 \\
\hline & Gephyrin UMAP2 & Untreated vs TTX & Normal & $\begin{array}{c}\text { Permutation } \\
t \text { test }\end{array}$ & 5000 & 0.261 & -0.03 & -0.08 & 0.02 & -0.68 & -2.13 & 0.68 & 0.2 & & 6 & 5 \\
\hline & Gephyrin UMAP3 & Untreated vs TTX & Normal & $\begin{array}{l}\text { Permutation } \\
t \text { test }\end{array}$ & 5000 & 0.345 & -0.03 & -0.08 & 0.02 & -0.61 & -1.96 & 0.76 & 0.1 & & 6 & 5 \\
\hline & Gephyrin UMAP4 & Untreated vs TTX & Normal & $\begin{array}{l}\text { Permutation } \\
t \text { test }\end{array}$ & 5000 & 0.304 & 0.02 & -0.02 & 0.06 & 0.69 & -1.58 & 2.43 & 0.2 & & 6 & 5 \\
\hline & Gephyrin UMAP5 & Untreated vs TTX & Normal & $\begin{array}{l}\text { Permutation } \\
t \text { test }\end{array}$ & 5000 & 0.647 & 0.02 & -0.05 & 0.08 & 0.30 & -1.82 & 2.69 & 0.1 & & 6 & 5 \\
\hline & Gephyrin UMAP6 & Untreated vs TTX & Normal & $\begin{array}{l}\text { Permutation } \\
t \text { test }\end{array}$ & 5000 & 0.733 & 0.03 & -0.12 & 0.25 & 0.20 & -1.41 & 1.56 & 0.1 & & 6 & 5 \\
\hline & $\begin{array}{c}\text { Homer1-b/c } \\
\text { UMAP1 }\end{array}$ & Untreated vs TTX & Normal & $\begin{array}{l}\text { Permutation } \\
t \text { test }\end{array}$ & 5000 & 0.221 & 0.09 & -0.05 & 0.23 & 0.81 & -0.89 & 2.60 & 0.2 & & 6 & 5 \\
\hline & $\begin{array}{c}\text { Homer1-b/c } \\
\text { UMAP1 }\end{array}$ & Untreated vs TTX & Normal & $\begin{array}{l}\text { Permutation } \\
t \text { test }\end{array}$ & 5000 & 0.452 & 0.00 & 0.00 & 0.00 & -0.81 & -1.64 & -0.40 & 0.2 & & 6 & 5 \\
\hline & $\begin{array}{c}\text { Homer1-b/c } \\
\text { UMAP1 }\end{array}$ & Untreated vs TTX & Normal & $\begin{array}{l}\text { Permutation } \\
t \text { test }\end{array}$ & 5000 & 0.438 & 0.05 & -0.07 & 0.16 & 0.49 & -1.17 & 2.16 & 0.1 & & 6 & 5 \\
\hline & $\begin{array}{c}\text { Homer1-b/c } \\
\text { UMAP1 }\end{array}$ & Untreated vs TTX & Normal & $\begin{array}{l}\text { Permutation } \\
t \text { test }\end{array}$ & 5000 & 0.660 & 0.01 & -0.04 & 0.08 & 0.29 & -1.70 & 2.07 & 0.1 & & 6 & 5 \\
\hline & $\begin{array}{c}\text { Homer1-b/c } \\
\text { UMAP1 }\end{array}$ & Untreated vs TTX & Normal & $\begin{array}{l}\text { Permutation } \\
t \text { test }\end{array}$ & 5000 & 0.474 & 0.02 & -0.05 & 0.08 & 0.41 & -1.23 & 2.01 & 0.1 & & 6 & 5 \\
\hline & $\begin{array}{l}\text { Homer1-b/c } \\
\text { UMAP1 }\end{array}$ & Untreated vs TTX & Normal & $\begin{array}{l}\text { Permutation } \\
t \text { test }\end{array}$ & 5000 & 0.031 & 0.19 & 0.07 & 0.29 & 1.80 & 0.48 & 4.20 & 0.8 & * & 6 & 5 \\
\hline & NR2B UMAP1 & Untreated vs TTX & Normal & $\begin{array}{l}\text { Permutation } \\
t \text { test }\end{array}$ & 5000 & 0.144 & 0.10 & -0.03 & 0.22 & 0.97 & -0.48 & 2.77 & 0.3 & & 6 & 5 \\
\hline & NR2B UMAP2 & Untreated vs TTX & Normal & $\begin{array}{l}\text { Permutation } \\
t \text { test }\end{array}$ & 5000 & 0.827 & -0.02 & -0.14 & 0.11 & -0.15 & -1.71 & 1.68 & 0.1 & & 6 & 5 \\
\hline & NR2B UMAP3 & Untreated vs TTX & Normal & $\begin{array}{l}\text { Permutation } \\
t \text { test }\end{array}$ & 5000 & 0.312 & 0.07 & -0.04 & 0.17 & 0.63 & -0.95 & 2.41 & 0.2 & & 6 & 5 \\
\hline & NR2B UMAP4 & Untreated vs TTX & Normal & $\begin{array}{l}\text { Permutation } \\
\quad t \text { test }\end{array}$ & 5000 & 0.661 & 0.05 & -0.18 & 0.28 & 0.26 & -1.50 & 2.35 & 0.1 & & 6 & 5 \\
\hline & NR2B UMAP5 & Untreated vs TTX & Normal & $\begin{array}{l}\text { Permutation } \\
t \text { test }\end{array}$ & 5000 & 0.744 & -0.03 & -0.20 & 0.12 & -0.20 & -1.80 & 1.34 & 0.1 & & 6 & 5 \\
\hline & NR2B UMAP6 & Untreated vs TTX & Normal & $\begin{array}{c}\text { Permutation } \\
t \text { test }\end{array}$ & 5000 & 0.533 & 0.14 & -0.33 & 0.54 & 0.37 & -1.08 & 1.97 & 0.1 & & 6 & 5 \\
\hline & & & & & & Continu & & & & & & & & & & \\
\hline
\end{tabular}


Table 4: Continued

Data Group comparison structure Type of test Shuffl

Figure Target

PSD-95 UMAP1

PSD-95 UMA

PSD-95 UMAP3 $t$ test

PSD-95 UMAP4

PSD-95 UMAP5

PSD-95 UMAP6

SHANK3 UMAP

SHANK3 UMAP2

SHANK3 UMAP

SHANK3 UMAP

SHANK3 UMAP5

SHANK3 UMAP6

Actin UMAP1

Actin UMAP2

Actin UMAP3

Actin UMAP4

Actin UMAP5

Actin UMAP6

Bassoon UMAP1

Bassoon UMAP2

Bassoon UMAP3

Bassoon UMAP4

Bassoon UMAP

Bassoon UMAP6

Cortactin UMAP

Cortactin UMAP2

Cortactin UMAP

Cortactin UMAP4

Cortactin UMAP

Cortactin UMAP
Untreated vs TTX

Untreated vs TTX Normal Permutation 5000 $t$ test

Untreated vs TTX Normal Permutation 5000 $t$ test

Untreated vs TTX Normal Permutation 5000 $t$ test

Untreated vs TTX Normal Permutation 5000 $t$ test

Untreated vs TTX Normal Permutation 5000 $t$ test

Untreated vs TTX Normal Permutation 5000 $t$ test

Untreated vs TTX Normal Permutation 5000 $t$ test

Untreated vs TTX Normal Permutation 5000 $t$ test

Untreated vs TTX Normal Permutation 5000 $t$ test

Untreated vs TTX Normal Permutation 5000 $t$ test

Permutation 5000 $t$ test

ntreated vs TTX Normal Permutation 5000 $t$ test

Untreated vs TTX Normal Permutation 5000 $t$ test

Untreated vs TTX Normal Permutation 5000 $t$ test

Untreated vs TTX Normal Permutation 5000 $t$ test

Untreated vs TTX Normal Permutation 5000 $t$ test

Untreated vs TTX Normal Permutation 5000 $t$ test

Untreated vs TTX Normal Permutation 5000 $t$ test

Permutation 5000 $t$ test

Permutation 5000 $t$ test

Permutation 5000 $t$ test

Permutation 5000 $t$ test

Permutation 5000

$t$ test

Permutation 5000 $t$ test

Permutation 5000 $t$ test

Permutation 5000 $t$ test

Permutation 5000 $t$ test

Permutation 5000 $t$ test

$\begin{array}{lrr}\text { Untreated vs TTX } & \text { Normal } & \begin{array}{r}\text { Permutation } \\ t \text { test }\end{array} \\ \text { Untreated vs TTX } & \text { Normal } & \text { Permutation }\end{array}$

Mean

$\begin{array}{crl} & \text { Effect (Cohen's d) } \\ 95 \% \mathrm{Cl} & 95 \% \mathrm{Cl} & 95 \% \mathrm{Cl} \quad 95 \% \mathrm{Cl}\end{array}$

Effect lower upper Power $p<0.05$ UT TTX

$p$ value Difference lower

upper

$\begin{array}{ll}0.313 & 0.06\end{array}$

$\begin{array}{ll}-0.04 & 0.17\end{array}$

$\begin{array}{llll}0.65 & -0.85 & 2.04 & 0.2\end{array}$

65

$0.053 \quad 0.06$

$0.01 \quad 0.11$

$1.43-0.33$

$3.18 \quad 0.6$

65

$\begin{array}{llll}0.778 & 0.02 & -0.10 & 0.15\end{array}$

$\begin{array}{llll}0.17 & -1.28 & 1.56 & 0.1\end{array}$

$6 \quad 5$

$0.882 \quad 0.00$

$\begin{array}{llllll}0.00 & 0.00 & -0.12 & -1.47 & 1.58 & 0.1\end{array}$

65

$0.184 \quad 0.00$

$\begin{array}{llllll}0.00 & 0.01 & 0.86 & 0.40 & 1.50 & 0.2\end{array}$

65

$0.729-0.01$

$\begin{array}{llllll}-0.08 & 0.07 & -0.21 & -1.69 & 1.26 & 0.1\end{array}$

65

$0.018 \quad 0.23$

$0.11 \quad 0.35$

$2.07 \quad 0.81 \quad 4.11 \quad 0.9$

65

$0.011 \quad 0.10$

$0.04 \quad 0.15$

$\begin{array}{llll}1.94 & 0.55 & 3.24 & 0.8\end{array}$

65

$0.019 \quad 0.20$

$0.08 \quad 0.30$

$1.85 \quad 0.55$

$4.35 \quad 0.8$

65

$0.186 \quad 0.06$

$-0.03 \quad 0.14$

$\begin{array}{llll}0.85 & -0.62 & 2.44 & 0.2\end{array}$

65

$\begin{array}{llllllll}0.285 & 0.06 & -0.04 & 0.16 & 0.67 & -0.80 & 2.17 & 0.2\end{array}$

65

$\begin{array}{llllllll}0.360 & 0.07 & -0.06 & 0.22 & 0.58 & -0.84 & 2.15 & 0.1\end{array}$

65

$\begin{array}{llllllll}0.345 & -0.10 & -0.28 & 0.06 & -0.60 & -1.95 & 1.11 & 0.1\end{array}$

65

$\begin{array}{llllllll}0.927 & 0.00 & -0.05 & 0.06 & -0.06 & -1.54 & 1.59 & 0.1\end{array}$

65

$\begin{array}{llllllll}0.407 & -0.06 & -0.18 & 0.06 & -0.56 & -2.01 & 1.13 & 0.1\end{array}$

65

$\begin{array}{llllllll}0.721 & -0.01 & -0.07 & 0.05 & -0.21 & -1.70 & 1.26 & 0.1\end{array}$

65

$0.923-0.01$

$-0.18 \quad 0.07$

$\begin{array}{llll}-0.11 & -1.72 & 2.14 & 0.1\end{array}$

65

$\begin{array}{llllllll}0.876 & 0.01 & -0.14 & 0.19 & 0.10 & -1.31 & 1.65 & 0.1\end{array}$

65

$\begin{array}{llllllll}0.250 & 0.08 & -0.04 & 0.21 & 0.74 & -0.90 & 1.94 & 0.2\end{array}$

65

$\begin{array}{llllllll}0.593 & -0.02 & -0.11 & 0.06 & -0.33 & -1.97 & 1.56 & 0.1\end{array}$

65

$0.064 \quad 0.09$

$0.02 \quad 0.22$

$\begin{array}{llll}1.16 & -0.33 & 2.12 & 0.4\end{array}$

65

$\begin{array}{llllllll}0.877 & 0.01 & -0.09 & 0.13 & 0.09 & -2.47 & 3.45 & 0.1\end{array}$

65

$\begin{array}{llllllll}0.569 & 0.02 & -0.05 & 0.08 & 0.33 & -1.26 & 2.33 & 0.1\end{array}$

65

$\begin{array}{llllllll}0.281 & 0.07 & -0.06 & 0.19 & 0.64 & -0.83 & 2.20 & 0.2\end{array}$

65

$\begin{array}{llllllll}0.201 & -0.09 & -0.24 & 0.01 & -0.84 & -2.03 & 0.63 & 0.2\end{array}$

65

$\begin{array}{llllllll}0.573 & -0.02 & -0.11 & 0.05 & -0.34 & -1.81 & 1.07 & 0.1\end{array}$

$6 \quad 5$

$\begin{array}{llllllll}0.390 & 0.00 & 0.00 & 0.00 & 0.55 & -0.98 & 2.37 & 0.1\end{array}$

65

$0.867-0.00$

$\begin{array}{llllll}0.00 & 0.00 & 0.11 & -1.21 & 1.57 & 0.1\end{array}$

65

65

$\begin{array}{llllllll}0.781 & -0.02 & -0.12 & 0.11 & -0.16 & -2.09 & 1.78 & 0.1\end{array}$

65 
Table 4: Continued

\begin{tabular}{|c|c|c|c|c|c|c|c|c|c|c|c|c|c|c|c|c|c|}
\hline & \multirow[b]{2}{*}{ Figure } & \multirow[b]{2}{*}{ Target } & \multirow[b]{2}{*}{ Group comparison } & \multirow[b]{2}{*}{$\begin{array}{l}\text { Data } \\
\text { structure }\end{array}$} & \multirow[b]{2}{*}{ Type of test } & \multirow[b]{2}{*}{ Shuffles } & \multirow[b]{2}{*}{$p$ value } & \multirow{2}{*}{$\begin{array}{l}\text { Mean } \\
\text { Difference }\end{array}$} & \multicolumn{6}{|c|}{ Effect (Cohen's $d$ ) } & \multirow[b]{2}{*}{$p<0.05$} & \multirow{2}{*}{$\begin{array}{l}N \\
\text { UT }\end{array}$} & \multirow[b]{2}{*}{ TTX } \\
\hline & & & & & & & & & $\begin{array}{l}95 \% \mathrm{Cl} \\
\text { lower }\end{array}$ & $\begin{array}{l}95 \% \mathrm{Cl} \\
\text { upper }\end{array}$ & Effect & $\begin{array}{l}95 \% \mathrm{Cl} \\
\text { lower }\end{array}$ & $\begin{array}{l}95 \% \mathrm{Cl} \\
\text { upper }\end{array}$ & Power & & & \\
\hline & & vGlut1 UMAP1 & Untreated vs TTX & Normal & $\begin{array}{l}\text { Permutation } \\
t \text { test }\end{array}$ & 5000 & 0.044 & 0.19 & 0.01 & 0.30 & 1.49 & -0.25 & 3.75 & 0.6 & * & 6 & 5 \\
\hline & & vGlut1 UMAP2 & Untreated vs TTX & Normal & $\begin{array}{l}\text { Permutation } \\
t \text { test }\end{array}$ & 5000 & 0.252 & 0.03 & -0.02 & 0.08 & 0.78 & -0.83 & 2.69 & 0.2 & & 6 & 5 \\
\hline & & vGlut1 UMAP3 & Untreated vs TTX & Normal & $\begin{array}{l}\text { Permutation } \\
t \text { test }\end{array}$ & 5000 & 0.045 & 0.08 & 0.01 & 0.16 & 1.38 & -0.39 & 3.00 & 0.5 & * & 6 & 5 \\
\hline & & vGlut1 UMAP4 & Untreated vs TTX & Normal & $\begin{array}{l}\text { Permutation } \\
t \text { test }\end{array}$ & 5000 & 0.231 & 0.03 & -0.02 & 0.07 & 0.77 & -0.83 & 2.44 & 0.2 & & 6 & 5 \\
\hline & & vGlut1 UMAP5 & Untreated vs TTX & Normal & $\begin{array}{l}\text { Permutation } \\
t \text { test }\end{array}$ & 5000 & 0.722 & 0.01 & -0.05 & 0.09 & 0.21 & -2.28 & 3.33 & 0.1 & & 6 & 5 \\
\hline & & vGlut1 UMAP6 & Untreated vs TTX & Normal & $\begin{array}{l}\text { Permutation } \\
t \text { test }\end{array}$ & 5000 & 0.358 & -0.01 & -0.02 & 0.01 & -0.57 & -2.24 & 1.05 & 0.1 & & 6 & 5 \\
\hline & & vGAT UMAP1 & Untreated vs TTX & Normal & $\begin{array}{l}\text { Permutation } \\
t \text { test }\end{array}$ & 5000 & 0.386 & 0.00 & -0.01 & 0.00 & -0.60 & -1.69 & 1.01 & 0.1 & & 6 & 5 \\
\hline & & vGAT UMAP2 & Untreated vs TTX & Normal & $\begin{array}{l}\text { Permutation } \\
t \text { test }\end{array}$ & 5000 & 0.883 & 0.00 & 0.00 & 0.00 & 0.08 & -1.41 & 1.55 & 0.1 & & 6 & 5 \\
\hline & & vGAT UMAP3 & Untreated vs TTX & Normal & $\begin{array}{l}\text { Permutation } \\
t \text { test }\end{array}$ & 5000 & 0.101 & -0.01 & -0.02 & 0.00 & -1.03 & -1.98 & 0.55 & 0.3 & & 6 & 5 \\
\hline & & vGAT UMAP4 & Untreated vs TTX & Normal & $\begin{array}{l}\text { Permutation } \\
t \text { test }\end{array}$ & 5000 & 0.861 & 0.00 & 0.00 & 0.01 & 0.06 & -1.31 & 1.57 & 0.1 & & 6 & 5 \\
\hline & & vGAT UMAP5 & Untreated vs TTX & Normal & $\begin{array}{l}\text { Permutation } \\
t \text { test }\end{array}$ & 5000 & 0.101 & -0.01 & -0.01 & 0.00 & -1.13 & -2.16 & -0.49 & 0.4 & & 6 & 5 \\
\hline & & vGAT UMAP6 & Untreated vs TTX & Normal & $\begin{array}{l}\text { Permutation } \\
t \text { test }\end{array}$ & 5000 & 0.002 & 0.86 & 0.61 & 1.08 & 3.99 & 2.55 & 6.30 & 1.0 & * & 6 & 5 \\
\hline \multirow[t]{6}{*}{ e } & $5 C$ & $\begin{array}{l}\text { UMAP1 synapse } \\
\text { number }\end{array}$ & Untreated vs TTX & Normal & $\begin{array}{l}\text { Permutation } \\
t \text { test }\end{array}$ & 5000 & 0.117 & 0.11 & 0.01 & 0.22 & 1.09 & -0.56 & 2.56 & 0.4 & & 6 & 5 \\
\hline & & $\begin{array}{l}\text { UMAP2 synapse } \\
\text { number }\end{array}$ & Untreated vs TTX & Normal & $\begin{array}{l}\text { Permutation } \\
t \text { test }\end{array}$ & 5000 & 0.042 & -0.27 & -0.47 & -0.04 & -1.52 & -3.59 & 0.15 & 0.6 & * & 6 & 5 \\
\hline & & $\begin{array}{l}\text { UMAP3 synapse } \\
\text { number }\end{array}$ & Untreated vs TTX & Normal & $\begin{array}{l}\text { Permutation } \\
t \text { test }\end{array}$ & 5000 & 0.092 & 0.23 & 0.07 & 0.53 & 1.17 & 0.10 & 2.19 & 0.4 & & 6 & 5 \\
\hline & & $\begin{array}{l}\text { UMAP4 synapse } \\
\text { number }\end{array}$ & Untreated vs TTX & Normal & $\begin{array}{l}\text { Permutation } \\
t \text { test }\end{array}$ & 5000 & 0.091 & -0.14 & -0.28 & 0.03 & -1.13 & -3.51 & 0.56 & 0.4 & & 6 & 5 \\
\hline & & $\begin{array}{l}\text { UMAP5 synapse } \\
\text { number }\end{array}$ & Untreated vs TTX & Normal & $\begin{array}{l}\text { Permutation } \\
t \text { test }\end{array}$ & 5000 & 0.002 & -0.42 & -0.60 & -0.30 & -3.12 & -4.32 & -1.96 & 1.0 & * & 6 & 5 \\
\hline & & $\begin{array}{l}\text { UMAP6 synapse } \\
\text { number }\end{array}$ & Untreated vs TTX & Normal & $\begin{array}{l}\text { Permutation } \\
t \text { test }\end{array}$ & 5000 & 0.428 & 0.12 & -0.11 & 0.42 & 0.51 & -0.84 & 1.85 & 0.1 & & 6 & 5 \\
\hline
\end{tabular}

Two-tailed permutation $t$ tests, mean confidence intervals, and effect size were calculated the from 5000 reshuffles of the untreated $(n=6)$ and TTX-treated $(n=5)$ samples. The $p$ values represent the likelihood of observing the reported effect size, if the null hypothesis of zero difference is true. Power analysis represents the probability of observing effect size if the null hypothesis of zero difference is true.

and to examine the response of 11 synaptic targets simultaneously following induction of homeostatic synaptic plasticity. Interestingly, using relative intensity measurements to evaluate protein abundance, we observed different patterns of response to neuronal activity blockade depending whether proteins are present at excitatory or inhibitory synapses or are presynaptic or postsynaptic (Fig. 4C). The neurotransmitter transporters at presynaptic excitatory and inhibitory terminals, vGlut1 and vGAT, respectively, both show a significant increase in response to TTX treatment. In contrast, synapsin1, a protein associated with the reserve pool of synaptic vesicles, shows increased levels in response to TTX treatment exclusively at inhibitory synapses. Additionally, at both excitatory and inhibitory synapses there was no change in the levels of the presynaptic protein bassoon. However, overall bassoon levels were lower at inhibitory synapses compared with excitatory synapses. On the postsynaptic side, the levels of the excitatory scaffolding proteins SHANK3, homer-1b/c, and PSD-95 increased in the presence of
TTX, while no changes in the inhibitory postsynaptic scaffold gephyrin were observed at inhibitory synapses. Interestingly, no changes were observed in the cytoskeletal proteins cortactin and actin at excitatory or inhibitory synapses (Fig. 4C; Table 4, c). Thus, we observe that excitatory synapses respond both postsynaptically and presynaptically to neuronal activity suppression while at inhibitory synapses the response is mainly presynaptic.

\section{Alterations in excitatory and inhibitory synapses within synaptic subgroups following activity blockade}

We further assessed the effect of activity blockage via TTX on synaptic subtypes and found that the same clusters described in control neurons are present after chronic neuronal activity blockage (Fig. 5). Analysis of synaptic intensity revealed no differences for most synaptic targets within each cluster (Fig. 5B; Table 4, d). Instead, we found that following 48-h TTX treatment, the number of synapses present in each cluster changed. Specifically, there 
A

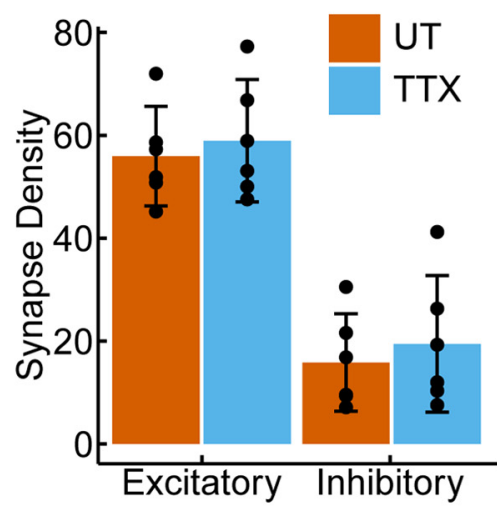

B

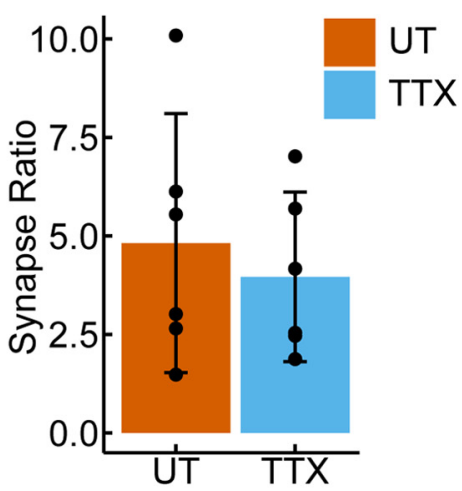

C

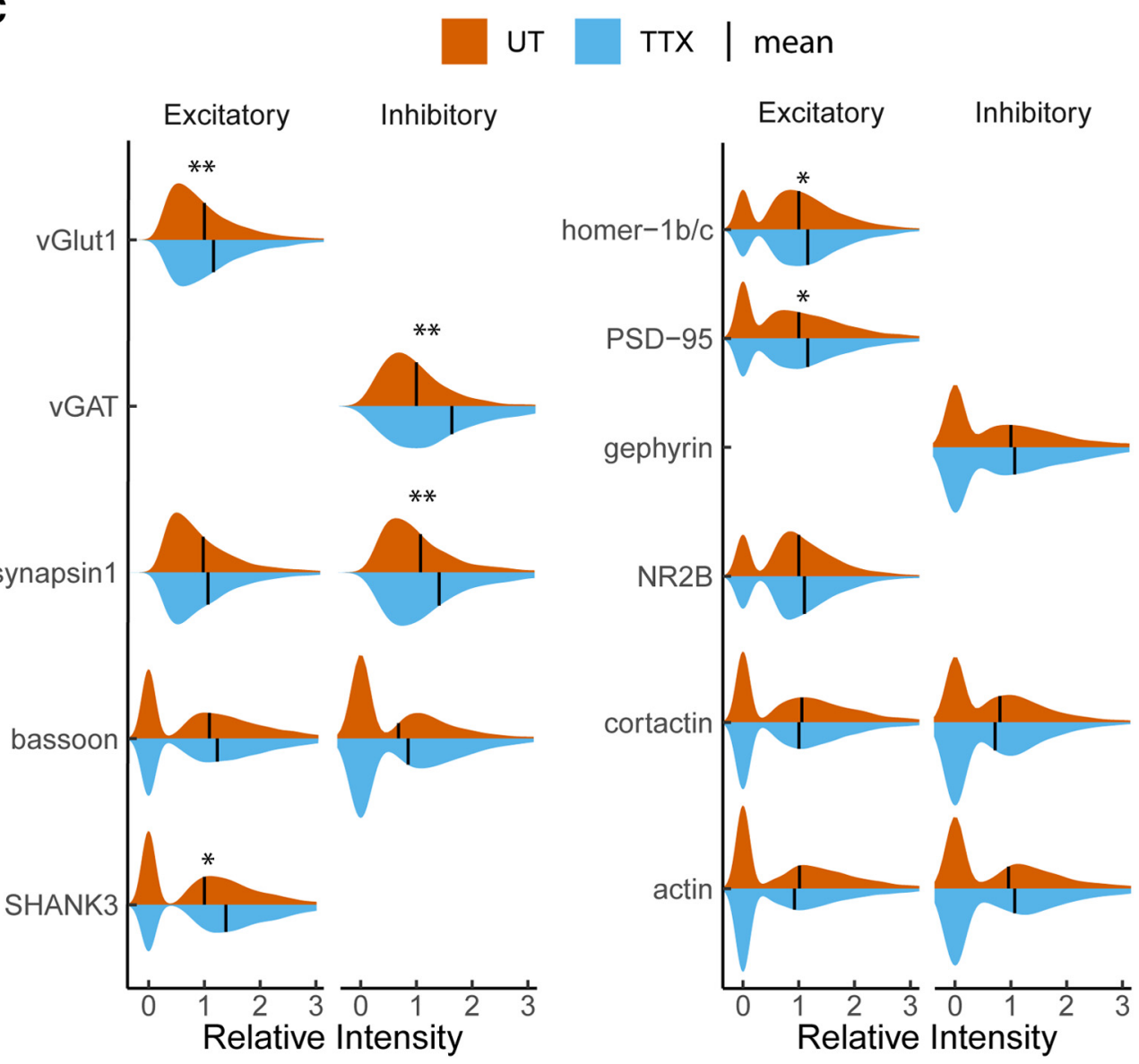

Figure 4. Excitatory and inhibitory synaptic density does not change in response to 48-h TTX treatment. A, Quantification of excitatory and inhibitory synaptic density from untreated (red) and TTX-treated (blue) cells. Bar height represents the mean number of synapses per 100- $\mu \mathrm{m}$ length of dendrite. B, Quantification of the excitatory:inhibitory synaptic ratio in untreated (red) and TTX-treated (blue) neurons. Bar height represents mean excitatory:inhibitory ratio. Error bars indicate $95 \%$ confidence intervals. Closed circles indicate results from individual replicates $n=6$. $\boldsymbol{C}$, Violin plots of relative synaptic intensity for synaptic targets at excitatory synapses (left) and inhibitory synapses (right) from untreated (red) and TTX-treated cells (blue). Black line indicates the mean intensity; $p$ values are computed using Student's $t$ test on the mean Integrated Intensity with $n=6(\mathrm{UT})$ and $n=5$ (TTX) replicates. All values are normalized to untreated mean integrated intensity; ${ }^{* *} p<0.01,{ }^{\star} p<0.05$.

was a small decrease in the number of synapses within Clusters 2, 4, and $5(p<0.05, p=0.09$, and $p<0.001$; Fig. 5C; Table 4, e). Taken together, the results indicate that TTX treatment does not produce unique synaptic subtypes (based on the proteins we examined), but it does change the number of synapses present within each cluster, specifically, reducing the number of synapses in clusters defined by low protein expression. 
A

\section{Untreated}

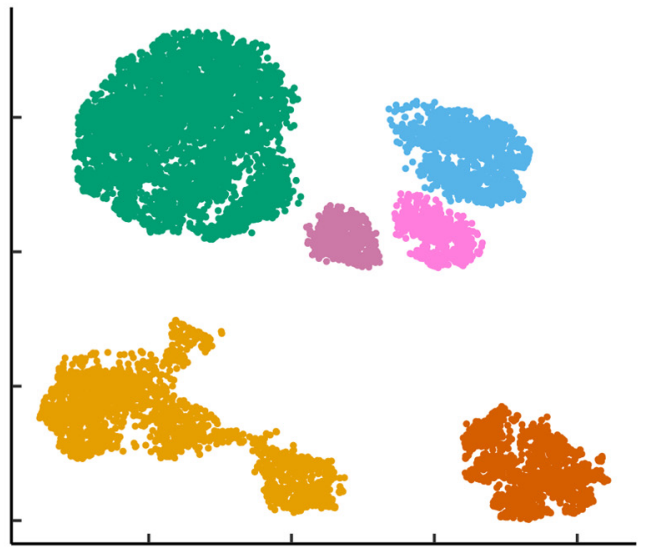

TTX
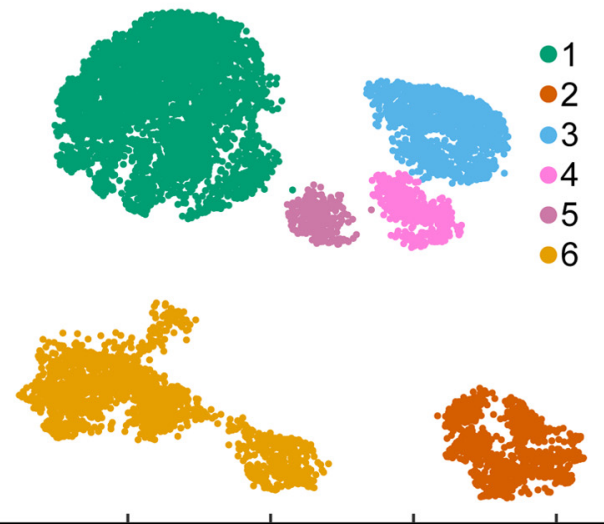

B
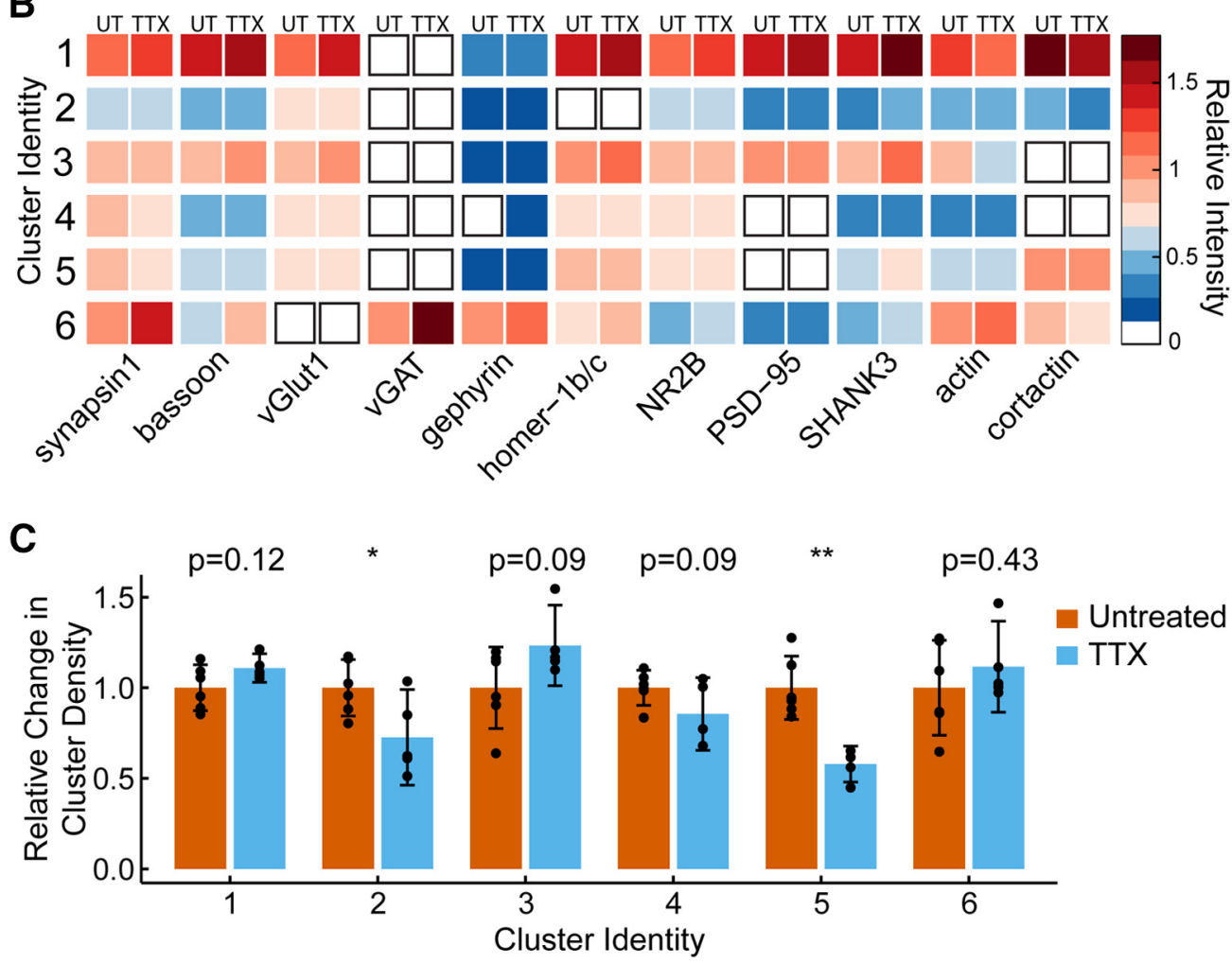

Figure 5. Characterizing changes within clusters in response to TTX treatment. $\boldsymbol{A}$, UMAP plots of individual synapses $(n=10,000)$ separated by treatment group. $\boldsymbol{B}$, Heatmap indicates the average relative intensities for each synaptic target within each cluster. Left side of the column is the untreated sample, the right side of the column is the TTX-treated sample. All values are normalized to untreated mean integrated intensity. $\boldsymbol{C}$, Bar heights show synapse density, relative to untreated groups, within each HDBSCAN identified cluster following TTX treatment; $p$ values are computed using Student's $t$ test with $n=6$ (UT) and $n=5$ (TTX) replicates; ${ }^{\star *} p<0.01,{ }^{*} p<0.05$. Error bars indicate $95 \%$ confidence intervals.

\section{Discussion}

We simultaneously characterized inhibitory and excitatory synaptic content from multiplexed imaging using PRISM and CellProfiler, offering detailed molecular insight into synapse complexity at the single-synapse level, including excitatory and inhibitory components.

Synapse identification using synapsin1 in combination with either vGlut1 or vGAT indicated an E/l ratio of $\sim 5 \pm 3: 1$ in hippocampal neurons. In cultured neurons, the $\mathrm{E} / \mathrm{I}$ ratio reported using imaging techniques is variable and dependent on multiple factors such as brain region and the age of the culture. In hippocampal culture, E/I ratios range between 2.5:1 and 17:1 (Gulyás et al., 1999; Megías et al., 2001; Liu, 2004; Harrill et al., 2015), which may be a consequence of the synaptic distribution variations of across the dendrites with fewer synapses located proximal than distal segments (Megías et al., 2001; Bloss et al., 2016). In agreement with this, the methodology 
implemented here provides the overall E/I ratios from whole synapse populations based on the use of several protein markers simultaneously.

Beyond E/I ratios, simultaneous imaging of 11 synaptic components enabled the identification and labeling of synapses based on synaptic content, and characterization of unique changes within these synapse subpopulations in response to chemical perturbation. Considering only those synapses that met the classification criteria for excitatory and inhibitory described here, we were able to identify five types of excitatory synapses and one type of inhibitory synapse based on the differential expression patterns of the targets specifically selected for this study. These synaptic targets, which are all major components of synapses, have been extensively studied for their role in synapse structure and function (Sheng and Hoogenraad, 2007; Sheng and Kim, 2011). Although the significance of these clusters may require additional studies because of the disproportionate complexity of the synaptic proteome (Husi et al., 2000; Peng et al., 2004; Collins et al., 2005, 2006; Emes and Grant, 2011; Distler et al., 2014). Notwithstanding, our analysis offers a framework for deciphering orchestrated compensatory changes that occur during synaptic scaling.

An additional layer of complexity that requires consideration, when classifying synapses using protein levels and correlation analysis, is the highly dynamic and plastic nature of synapses (Nimchinsky et al., 2002). Given this framework, the clusters we identified may represent synapses captured in various stages of remodeling, which may explain the diversity observed, especially regarding excitatory synapse subtypes. Another factor to consider is the influence of developmental factors on the morphologic, structural, and proteomic characteristics of synapses. Thus, an alternative interpretation of these clusters is that we captured synapses from various developmental stages.

We must also acknowledge the possibility that, because of the variation of antibody epitope specificity among different host species and purification methods, some of the identified clusters may indicate contamination from staining artifacts. While visual inspection of these synapses does not present any evidence to suggest this is the case, assessing detection of false positives could serve as a useful tool for improving accuracy.

Another interesting observation from our results is that excitatory synapses seem to be more heterogeneous than inhibitory synapses. Excitatory synapses present more diverse morphologies, which could account for the increased variation. However, we only incorporated two inhibitory markers, vGAT and gephyrin, which would limit the number of inhibitory clusters that could be detected. While these interpretations represent exciting possibilities for examination of synapse biology, further experimentation to test these hypotheses are critical to address all these different aspects associated with synapse diversity classification.

Another unexpected advantage of the platform implemented here is that it also provides a tool for the simultaneous examination of the population of dually innervated synapses, originally described by electron microscopy (Kubota et al., 2016; Villa et al., 2016). This population, observed here as positive for both vGlut1 and vGAT (12\%), will likely require detailed characterization using super-resolution microscopy to overcome limitation of the spinning-disk confocal microscope used in this study (lateral resolution $=420 \mathrm{~nm}$ ). Thus, this platform could be used in tandem with DNA-PRISM, which also has super-resolution capabilities (Guo et al., 2019).

Confocal imaging for each neuronal imaging experiment was conducted using a $63 \times$ objective with 1.15 numerical aperture. At the wavelengths imaged, we were able to examine large fields of view while also resolving smaller, synaptic structures above the diffraction limit. At this magnification it is impossible to ensure that all detected synapses are isolated, independent synaptic units. Nevertheless, within the confines of this common imaging limitation that is intrinsic to confocal, diffraction-limited imaging, PRISM multiplexing was still able to provide a significant improvement on conventional imaging because of its ability to resolve excitatory and inhibitory synapses simultaneously, and exclude dual synapses containing both markers from our analysis. In addition, by sampling a large number of 22,000 synapses, the number of individually resolved synapses should offer robust classification of the synaptic subtypes identified using multiplexed protein expression profiles.

Our results revealed differences in the responses to activity blockade at excitatory and inhibitory synapses. At excitatory synapses, the synaptic levels of postsynaptic scaffolding proteins and presynaptic neurotransmitter transporter levels increased whereas there were no changes in bassoon levels or changes in the presynaptic vesicle clustering protein synapsin1. Our results suggest that, at excitatory synapses, neurons respond to activity blockade by increasing the amount of neurotransmitter present per vesicle and increasing the available postsynaptic AMPA receptor binding slots, but not by increasing the number of synaptic vesicles that are available for release. In contrast, inhibitory synapses showed both an increase in the neurotransmitters amount in the vesicle and an increase in the reserve pool of vesicles, indicated by synapsin1. Synapsin 1 has a critical function associated with the reserve pool of synaptic vesicles (Hilfiker et al., 1998; Bloom et al., 2003; Akbergenova and Bykhovskaia, 2007; Gitler et al., 2008), regulating mobilization of vesicles into the recycling pool (Chi et al., 2003; Cousin et al., 2003; Menegon et al., 2006; Baldelli et al., 2007), and forming clusters of vesicles that are reluctant to release unless high frequency stimulation is applied (Rizzoli and Betz, 2005). Increased synapsin1 at inhibitory synapses could therefore indicate reduced baseline GABAergic signaling consistent with the conventional model of synaptic scaling.

Synaptic diversity across various brain regions has been described previously using two postsynaptic markers PSD-95 and SAP102 (Zhu et al., 2018); however, a detailed characterization of synaptic diversity in cultured neurons and their response to changes in 
network activity with high-content imaging has not been addressed. An important component of homeostatic plasticity is that the resultant changes in excitability maintain the relative differences in synaptic strength between the individual synapses. Although no differences in the synapse diversity were observed in the presence of TTX treatment compared with control conditions; TTX was able to modify the clusters producing fewer synapses defined by low protein levels, consistent with the model that synaptic scaling induces global changes to increase synaptic strength. While this was true for synapses defined by our synaptic targets, there may be additional variations that require different targets for detection. While in vitro neuronal cultures lack the hierarchical organization and experience-driven plasticity that is present in vivo, in vitro models are effective tools for evaluating synapse development and plasticity quantitatively, as well as serving as a viable approach to perform large-scale drug and genetic screens. In the future, application of multiplexed imaging in vivo should offer increased power to assess synaptic heterogeneity, as well as reveal more physiologically relevant insight into neuronal plasticity.

In conclusion, PRISM facilitated the exploration of complex synaptic architecture, with the imaging and analysis platform described here revealing numerous synaptic subtypes and their molecular rearrangements in response to homeostatic scaling. Exploration of synaptic diversity in neurons enables a new range of investigations with the potential to reveal new connections between synaptic architecture and neuronal function that can be especially useful for high-content and high-throughput screening using compounds or siRNA libraries of genes associated with disease.

\section{References}

Akbergenova Y, Bykhovskaia M (2007) Synapsin maintains the reserve vesicle pool and spatial segregation of the recycling pool in Drosophila presynaptic boutons. Brain Res 1178:52-64.

Baldelli P, Fassio A, Valtorta F, Benfenati F (2007) Lack of synapsin I reduces the readily releasable pool of synaptic vesicles at central inhibitory synapses. J Neurosci 27:13520-13531.

Bayés À, van de Lagemaat LN, Collins MO, Croning MDR, Whittle IR, Choudhary JS, Grant SGN (2011) Characterization of the proteome, diseases and evolution of the human postsynaptic density. Nat Neurosci 14:19-21.

Bayés À, Collins MO, Croning MDR, van de Lagemaat LN, Choudhary JS, Grant SGN (2012) Comparative study of human and mouse postsynaptic proteomes finds high compositional conservation and abundance differences for key synaptic proteins. PLoS One 7:e46683.

Bayés À, Collins MO, Reig-Viader R, Gou G, Goulding D, Izquierdo A, Choudhary JS, Emes RD, Grant SGN (2017) Evolution of complexity in the zebrafish synapse proteome. Nat Commun 8:14613.

Bloom O, Evergren E, Tomilin N, Kjaerulff O, Löw P, Brodin L, Pieribone VA, Greengard P, Shupliakov O (2003) Colocalization of synapsin and actin during synaptic vesicle recycling. J Cell Biol 161:737-747.

Bloss EB, Cembrowski MS, Karsh B, Colonell J, Fetter RD, Spruston N (2016) Structured dendritic inhibition supports branch-selective integration in CA1 pyramidal cells. Neuron 89:1016-1030.

Champely S (2020) Pwr: basic functions for power analysis. Available form https://CRAN.R-project.org/package=pwr.
Chi P, Greengard P, Ryan TA (2003) Synaptic vesicle mobilization is regulated by distinct synapsin I phosphorylation pathways at different frequencies. Neuron 38:69-78.

Collins MO, Yu L, Coba MP, Husi H, Campuzano I, Blackstock WP, Choudhary JS, Grant SGN (2005) Proteomic analysis of in vivo phosphorylated synaptic proteins. J Biol Chem 280:5972-5982.

Collins MO, Husi H, Yu L, Brandon JM, Anderson CNG, Blackstock WP, Choudhary JS, Grant SGN (2006) Molecular characterization and comparison of the components and multiprotein complexes in the postsynaptic proteome. J Neurochem 97:16-23.

Cousin MA, Malladi CS, Tan TC, Raymond CR, Smillie KJ, Robinson PJ (2003) Synapsin I-associated phosphatidylinositol 3-kinase mediates synaptic vesicle delivery to the readily releasable pool. $J$ Biol Chem 278:29065-29071.

Davison AC, Hinkley DV (1997) Bootstrap methods and their applications. Cambridge: Cambridge University Press.

Distler U, Schmeisser MJ, Pelosi A, Reim D, Kuharev J, Weiczner R, Baumgart J, Boeckers TM, Nitsch R, Vogt J, Tenzer S (2014) Indepth protein profiling of the postsynaptic density from mouse hippocampus using data-independent acquisition proteomics. Proteomics 14:2607-2613.

Emes RD, Grant SGN (2011) The human postsynaptic density shares conserved elements with proteomes of unicellular eukaryotes and prokaryotes. Front Neurosci 5:44.

Emes RD, Grant SGN (2012) Evolution of synapse complexity and diversity. Annu Rev Neurosci 35:111-131.

Emes RD, Pocklington AJ, Anderson CNG, Bayes A, Collins MO, Vickers CA, Croning MDR, Malik BR, Choudhary JS, Armstrong JD, Grant SGN (2008) Evolutionary expansion and anatomical specialization of synapse proteome complexity. Nat Neurosci 11:799806.

Gerdes MJ, Sevinsky CJ, Sood A, Adak S, Bello MO, Bordwell A, Can A, Corwin A, Dinn S, Filkins RJ, Hollman D, Kamath V, Kaanumalle S, Kenny K, Larsen M, Lazare M, Li Q, Lowes C, McCulloch CC, McDonough E, et al. (2013) Highly multiplexed single-cell analysis of formalin-fixed, paraffin-embedded cancer tissue. Proc Natl Acad Sci USA 110:11982-11987.

Gitler D, Cheng Q, Greengard P, Augustine GJ (2008) Synapsin Ila controls the reserve pool of glutamatergic synaptic vesicles. J Neurosci 28:10835-10843.

Gulyás Al, Megías M, Emri Z, Freund TF (1999) Total number and ratio of excitatory and inhibitory synapses converging onto single interneurons of different types in the CA1 area of the rat hippocampus. J Neurosci 19:10082-10097.

Guo SM, Veneziano R, Gordonov S, Li L, Danielson E, Perez de Arce K, Park D, Kulesa AB, Wamhoff E-C, Blainey PC, Boyden ES, Cottrell JR, Bathe M (2019) Multiplexed and high-throughput neuronal fluorescence imaging with diffusible probes. Nat Commun 10:4377.

Harrill JA, Chen H, Streifel KM, Yang D, Mundy WR, Lein PJ (2015) Ontogeny of biochemical, morphological and functional parameters of synaptogenesis in primary cultures of rat hippocampal and cortical neurons. Mol Brain 8:10.

Hartman KN, Pal SK, Burrone J, Murthy VN (2006) Activity-dependent regulation of inhibitory synaptic transmission in hippocampal neurons. Nat Neurosci 9:642-649.

He HY, Cline HT (2019) What is excitation/inhibition and how is it regulated? A case of the elephant and the wisemen. J Exp Neurosci 13:1179069519859371.

He HY, Shen W, Zheng L, Guo X, Cline HT (2018) Excitatory synaptic dysfunction cell-autonomously decreases inhibitory inputs and disrupts structural and functional plasticity. Nat Commun 9:2893.

Hilfiker S, Schweizer FE, Kao HT, Czernik AJ, Greengard P, Augustine GJ (1998) Two sites of action for synapsin domain E in regulating neurotransmitter release. Nat Neurosci 1:29-35.

Husi H, Ward MA, Choudhary JS, Blackstock WP, Grant SG (2000) Proteomic analysis of NMDA receptor-adhesion protein signaling complexes. Nat Neurosci 3:661-669. 
Kassambara A (2019) Ggpubr: "ggplot2" based publication ready plots. Available from https://CRAN.R-project.org/package= ggpubr.

Konopka T (2019) Umap: uniform manifold approximation and projection. Available from https://CRAN.R-project.org/package=umap.

Kubota Y, Karube F, Nomura M, Kawaguchi Y (2016) The diversity of cortical inhibitory synapses. Front Neural Circuits 10:27.

Lin JR, Fallahi-Sichani M, Sorger PK (2015) Highly multiplexed imaging of single cells using a high-throughput cyclic immunofluorescence method. Nat Commun 6:8390.

Liu G (2004) Local structural balance and functional interaction of excitatory and inhibitory synapses in hippocampal dendrites. Nat Neurosci 7:373-379.

Mclnnes L, Healy J, Astels S (2017) Hdbscan: hierarchical density based clustering. J Open Source Softw 2:205.

McQuin C, Goodman A, Chernyshev V, Kamentsky L, Cimini BA, Karhohs KW, Doan M, Ding L, Rafelski SM, Thirstrup D, Wiegraebe W, Singh S, Becker T, Caicedo JC, Carpenter AE (2018) CellProfiler 3.0: next-generation image processing for biology. PLoS Biol 16:e2005970.

Megías M, Emri Z, Freund TF, Gulyás Al (2001) Total number and distribution of inhibitory and excitatory synapses on hippocampal CA1 pyramidal cells. Neuroscience 102:527-540.

Menegon A, Bonanomi D, Albertinazzi C, Lotti F, Ferrari G, Kao H-T, Benfenati F, Baldelli P, Valtorta F (2006) Protein kinase A-mediated synapsin I phosphorylation is a central modulator of $\mathrm{Ca} 2+-$ dependent synaptic activity. J Neurosci 26:11670-11681.

Nimchinsky EA, Sabatini BL, Svoboda K (2002) Structure and function of dendritic spines. Annu Rev Physiol 64:313-353.

Peng J, Kim MJ, Cheng D, Duong DM, Gygi SP, Sheng M (2004) Semiquantitative proteomic analysis of rat forebrain postsynaptic density fractions by mass spectrometry. J Biol Chem 279:2100321011.

Rizzoli SO, Betz WJ (2005) Synaptic vesicle pools. Nat Rev Neurosci 6:57-69.

Roy M, Sorokina O, McLean C, Tapia-González S, DeFelipe J, Armstrong J, Grant S (2018) Regional diversity in the postsynaptic proteome of the mouse brain. Proteomes 6:31.

Sheng M, Hoogenraad CC (2007) The postsynaptic architecture of excitatory synapses: a more quantitative view. Annu Rev Biochem 76:823-847.
Sheng M, Kim E (2011) The postsynaptic organization of synapses. Cold Spring Harb Perspect Biol 3:a005678.

Torchiano M (2016) Effsize - a package for efficient effect size computation. Zenodo

Turrigiano GG (2008) The self-tuning neuron: synaptic scaling of excitatory synapses. Cell 135:422-435.

Turrigiano G (2012) Homeostatic synaptic plasticity: local and global mechanisms for stabilizing neuronal function. Cold Spring Harb Perspect Biol 4:a005736.

Turrigiano GG, Leslie KR, Desai NS, Rutherford LC, Nelson SB (1998) Activity-dependent scaling of quantal amplitude in neocortical neurons. Nature 391:892-896.

Turrigiano GG, Nelson SB (2000) Hebb and homeostasis in neuronal plasticity. Curr Opin Neurobiol 10:358-364.

Turrigiano GG, Nelson SB (2004) Homeostatic plasticity in the developing nervous system. Nat Rev Neurosci 5:97-107.

Villa KL, Berry KP, Subramanian J, Cha JW, Oh WC, Kwon H-B, Kubota Y, So PTC, Nedivi E (2016) Inhibitory synapses are repeatedly assembled and removed at persistent sites in vivo. Neuron 89:756-769.

Warnes GR, Bolker B, Bonebakker L, Gentleman R, Huber W, Liaw A, Lumley $T$ (2020) Gplots: various R programming tools for plotting data. Available form https://CRAN.R-project.org/package= gplots.

Wickham H (2016) Ggplot2: elegant graphics for data analysis. Available form https://ggplot2.tidyverse.org.

Wilke CO (2018) Ggridges: ridgeline plots in "Ggplot2." Available form https://CRAN.R-project.org/package=ggridges.

Wing MK, Weston S, Williams A, Keefer C, Engelhardt A, Cooper T, Mayer Z (2019) Caret: classification and regression training. Available form https://CRAN.R-project.org/package=caret.

Zavalin A, Yang J, Hayden K, Vestal M, Caprioli RM (2015) Tissue protein imaging at $1 \mathrm{Mm}$ laser spot diameter for high spatial resolution and high imaging speed using transmission geometry MALDI TOF MS. Anal Bioanal Chem 407:2337-2342.

Zhou M, F Liang, XR Xiong, L Li, H Li, Z Xiao, HW Tao, Li I Zhang (2014) Scaling down of balanced excitation and inhibition by active behavioral states in auditory cortex. Nat Neurosci 17:841-850.

Zhu F, Cizeron M, Qu Z, Benavides-Piccione R, Kopanitsa MV, Skene NG, Koniaris B, DeFelipe J, Fransén E, Komiyama NH, Grant SGN (2018) Architecture of the mouse brain synaptome. Neuron 99:781-799.e10. 